\title{
Emerging role of gefitinib in the treatment of non-small-cell lung cancer (NSCLC)
}

This article was published in the following Dove Press journal:

Drug Design, Development and Therapy

18 May 2010

Number of times this article has been viewed

\section{Tiseo \\ M Bartolotti \\ F Gelsomino \\ P Bordi}

Medical Oncology Unit, University Hospital of Parma, Parma, Italy
Correspondence: Marcello Tiseo Medical Oncology Unit, University Hospital of Parma,Via Gramsci,

14, 43100 Parma, Italy

$\mathrm{Tel}+390521702316$

Fax +39052I 995448

Email mtiseo@ao.pr.it
Abstract: Most patients with non-small-cell lung cancer (NSCLC) present with advanced disease and their long-term prognosis remains poor. Epidermal growth factor receptor (EGFR)targeted therapies, such as gefitinib, have been subjected to comprehensive clinical development. Several phase II and III trials evaluated the clinical efficacy of gefitinib as monotherapy in pretreated patients with advanced NSCLC, as well as both monotherapy and combined with chemotherapy in chemotherapy-naive patients. A phase III trial (ISEL) in heavily pretreated advanced NSCLC patients demonstrated some improvement in survival with gefitinib compared with placebo; however, the difference was not statistically significant within the overall population. A large phase III trial in pretreated patients (INTEREST) demonstrated the non-inferiority of gefitinib in comparison with docetaxel for overall survival, together with an improved quality of life and tolerability profiles. In a large phase III trial (IPASS) in Asian chemotherapy-naive, never or former light-smoker patients with adenocarcinoma, gefitinib was more effective than carboplatin-paclitaxel in prolonging progression-free survival, particularly in patients harboring EGFR gene mutations. Gefitinib was a generally well tolerated treatment, with skin rash and diarrhea being the most common treatment adverse events. As a result, gefitinib is expected to have a large impact on the management of patients with advanced NSCLC, in particular in EGFR mutated patients.

Keywords: non-small-cell lung cancer, gefitinib, EGFR

\section{Introduction}

Lung cancer is still the main cause of cancer deaths in the world. ${ }^{1}$ Non-small-cell lung cancer (NSCLC) accounts for approximately $80 \%$ of all lung cancers and can be divided into three principal subtypes: adenocarcinoma, squamous-cell carcinoma and large cell carcinoma. ${ }^{2}$

At the time of diagnosis, about $75 \%$ of NSCLC patients present with locally advanced or metastatic disease. ${ }^{1}$ For most of these patients the only therapeutic option is based on chemotherapy alone. The aim of this treatment is to slow down the progression of the disease, to relieve the patients from the lung cancer symptoms and, whenever possible, to increase the overall survival.

A meta-analysis, published in 1995 and updated in 2008, affirmed the efficacy of first-line platinum-based chemotherapy in improving overall survival compared with best supportive care (BSC) in advanced NSCLC. ${ }^{3,4}$ Subsequently, survival differences were not demonstrated among the various platinum-based doublets, including a third-generation drug, such as paclitaxel, docetaxel, vinorelbine or gemcitabine..$^{5-7}$ 
Recently, after the publication of the ECOG 4599 and AVAIL trial results, bevacizumab has been approved for the first-line treatment of non-squamous NSCLC in association with platinum-based chemotherapy. ${ }^{8,9}$ Moreover, pemetrexed has been recently registered for the first-line treatment of non-squamous NSCLC in association with cisplatin, after the results obtained by Scagliotti and colleagues in a trial demonstrating the non-inferiority of this new combination compared to standard cisplatin-gemcitabine. ${ }^{10}$

For second-line therapy, docetaxel and pemetrexed have been approved for this indication. ${ }^{11}$ The recent ASCO guidelines for the treatment of advanced NSCLC recommend also the use of gefitinib or erlotinib, epidermal growth factor receptor (EGFR)-tyrosine-kinase inhibitors (TKIs), in second- or third-line settings. ${ }^{12}$

Aiming to obtain an improvement in NSCLC management and prognosis, researchers have investigated the role of molecular-targeted agents, such as inhibitors of specific cellular growth pathways, like that of EGFR and of vascular endothelial growth factor receptor (VEGFR).

EGFR is the cell-surface receptor for the epidermal growth factor family proteins. The interaction between the receptor and its ligands activates signal transduction pathways involved in cell proliferation and survival. Increased expression of EGFR has been found in $40 \%-80 \%$ of NSCLC. ${ }^{13}$ Therefore, different approaches have been developed in order to inhibit EGFR, such as competition for the extracellular domain by monoclonal antibodies (cetuximab) or the inhibition of EGFR tyrosine-kinase activity by small-molecules interacting with the intracellular domain (erlotinib and gefitinib). In this paper, we will review the phase II-III trial results obtained with gefitinib in the treatment of NSCLC.

\section{Mode of action and pharmacokinetic of gefitinib}

Gefitinib is an orally administered low-molecular-weight anilinoquinazoline that inhibits the phosphorylation and tyrosine-kinase activity of the intracellular ATP-binding domain of EGFR through competitive binding to this site. The inhibition of the receptor and its related downstream process is achieved at dosages of $250 \mathrm{mg} /$ day, while the maximal tolerable dosage, assessed in phase I trials, is $700 \mathrm{mg} /$ day. ${ }^{14}$ Pharmacokinetic studies found that gefitinib is adsorbed slowly and it reaches peak plasma concentration after 3-7 hours. Because of its biological half-life of about 28 hours, gefitinib is administered once in a day. ${ }^{15,16}$

Others trials were conducted in order to establish the tumor penetration of gefitinib. In one of these, gefitinib was administered orally for 28 days in patients with early NSCLC and, subsequently, the drug concentrations in surgically resected tumor samples and plasma were compared; the drug concentrations were higher in the tissues than in the plasma, proving that gefitinib is able to penetrate into tumor tissue efficiently. ${ }^{17}$

Gefitinib is metabolized principally by cytochrome P4503A4, while CYP3A5 and CYP2D6 are less involved. This is the reason why gefitinib metabolism can differ from patient to patient; ie, in consideration of inter-individual variability of CYP3A4 expression and activity. Therefore, inducers or inhibitors of this cytochrome can also influence the pharmacokinetics of this drug. ${ }^{18}$

Some studies demonstrated that gefitinib blocks selectively EGFR tyrosine-kinase (if compared with tyrosine-kinases of different receptors) and that it does not inhibit serine-threonine-kinases. ${ }^{19}$ Its activity determines an upregulation of a cell cycle inhibitor (p27) and a downregulation of a transcription factor (c-fos), resulting in arresting the cell cycle in G1 phase. ${ }^{20}$ EGFR works through two different downstream signaling pathways: MAP kinase cascade, that activates different genes linked to cell proliferation and survival, and PI3K-AKT cascade, in which phosphorylated AKT (p-AKT) inactivates proapoptotic proteins. In some studies, gefitinib was found to be more active on tumors with enhanced basal p-AKT activity. ${ }^{21}$ Moreover; gefitinib decreases levels of important angiogenesis factors, like VEGF. ${ }^{22}$

\section{Gefitinib as second- or third-line therapy IDEAL (IRESSA Dose Evaluation in Advanced Lung Cancer) I and 2 trials}

According to results of four phase I studies, ${ }^{16,23-25}$ two large, dose-randomized, double-blind multicenter phase II trials (IDEAL-1 and IDEAL-2) were conducted to evaluate the activity of gefitinib, $250 \mathrm{mg} /$ day versus $500 \mathrm{mg} /$ day, in pretreated patients with advanced NSCLC. ${ }^{26,27}$

The IDEAL-1 study was conducted in Europe and others countries (Japan, South Africa, Australia) and recruited 210 patients, while IDEAL-2 enrolled 221 patients in US. ${ }^{26,27}$ In the first study, activity and efficacy were similar between $250 \mathrm{mg}$ and $500 \mathrm{mg} .{ }^{26}$ The objective response rates (RR) were of $18.4 \%$ and $19 \%$, respectively, with a disease control rates (DCR) of $54.4 \%$ versus $51.4 \%$; median progression-free survival (PFS) was of 2.7 versus 2.8 months and median overall survival (OS) of 7.6 versus 8.0 months, for 250 and $500 \mathrm{mg}$, 
respectively. The symptom improvement rate was $40.3 \%$ for the $250 \mathrm{mg}$ group and $37 \%$ for the $500 \mathrm{mg}$ group.

Similar results were obtained in the IDEAL-2 trial, in which there was no significant difference in patients who received either 250 or $500 \mathrm{mg}$ dose of gefitinib in terms of symptom improvement (43\% versus 35\%), RR (12\% versus $9 \%$ ) and OS (7 versus 6 months). ${ }^{27}$

In both IDEAL- 1 and IDEAL- 2 , in $>70 \%$ of responding patients, the response occurred within the first 4 weeks. The response rates were durable, with a median duration of 13 months and 7 months for patients in IDEAL-1 and -2, respectively. ${ }^{26,27}$

Adverse events, such as skin reactions and diarrhea, were generally mild, reversible and manageable with a greater number of dose modifications or withdrawals in patients receiving gefitinib at dose of $500 \mathrm{mg} .^{26,27}$

From these trials emerged the first evidence about the major efficacy of gefitinib in some specific subgroups of patients, such as female gender, adenocarcinoma histological subtype and Asian ethnicity. In particular, in IDEAL-2 the RR was greater in adenocarcinoma than in other histologies ( $13 \%$ versus $4 \%, P=0.046)$ and in females compared with males $(19 \%$ versus $3 \%, P=0.001) .{ }^{27}$ In IDEAL- 1 , the odds of responders was almost 3.5 times higher for patients with adenocarcinoma than for patients with other tumor histologies (odds ratio, $\mathrm{OR}=3.45, P=0.021$ ) and 2.5 times higher for females than males $(\mathrm{OR}=2.65, P=0.017)$. In this trial, moreover, the RR was higher for Japanese than non-Japanese patients $(27.5 \%$ versus $10.4 \%, \mathrm{OR}=3.27, P=0.0023) .{ }^{26}$

Therefore, gefitinib showed in these trials meaningful anti-tumor activity associated with rapid symptom relief and improvement of quality of life in pretreated patients with advanced NSCLC. Concomitantly, the $250 \mathrm{mg} /$ day was safer and more tolerated than $500 \mathrm{mg} /$ day dose. So, the $250 \mathrm{mg}$ once daily dose was chosen for subsequent studies and gefitinib was registered in US and Japan for patients with advanced NSCLC as a second- or third-line treatment.

\section{Gefitinib versus placebo: ISEL (IRESSA Survival Evaluation in Lung Cancer) trial}

ISEL is a randomized, placebo-controlled, international multicenter phase III study designed to investigate the impact on survival of gefitinib versus best supportive care (BSC) as a second- or third-line treatment in patients with advanced NSCLC. ${ }^{28}$ In this trial 1,692 patients, who were refractory or intolerant to previous chemotherapy, were enrolled and assigned in a ratio of $2: 1$ to either gefitinib $250 \mathrm{mg} /$ day $(1,129)$ or placebo $(563)$ plus BSC. The primary endpoint was survival in the overall population and in patients with adenocarcinoma subtype.

Differences in the median survival did not reach a statistical significance, either in the overall population and in patients with adenocarcinoma histology (Table 1). However, patients treated with gefitinib had a significantly higher RR and longer time to treatment failure (Table 1).

On preplanned subgroup analyses, a longer survival time was observed for patients treated with gefitinib who were never-smokers $(P=0.012)$ and of Asian origin $(P=0.01)$ (Table 1). To highlight the possible role of Asian ethnicity as predictive factor of response to gefitinib, a subset analysis including patients of Asian origin (about 20\% of treated population) demonstrated that patients treated with gefitinib had a significant improvement in survival rate (9.5 versus 5.5 months; $P=0.010$ ), time to treatment failure (4.4 versus 2.2 months, $P=0.0084$ ) and tumor response (12.4 versus $2.1 \%) .{ }^{29}$ Gefitinib was well tolerated (see below; "Safety and tolerability").

Therefore, the results of the ISEL trial show that treatment with gefitinib was not associated with a significant increase in overall survival either in the overall population or in adenocarcinoma co-primary population. This result was disappointing given the finding of the phase III erlotinib study (NCIC-BR.21) which showed a 2-month increase in survival in previously treated patients with NSCLC. ${ }^{30}$ Several explanations have been considered for the different results of the two trials. Different patient populations were enrolled in the two studies, due to differences in the eligibility criteria. The ISEL trial required patients to have progressed on the previous line of chemotherapy during treatment or within 90 days, while the BR.21 trial did not. This may have unintentionally selected a patient population in the ISEL trial that was more refractory to treatment and less likely to benefit from additional treatment. Another potential explanation is that a suboptimal dose of gefitinib was investigated in the ISEL trial. The decision to proceed with the $250 \mathrm{mg}$ daily dose was based on a higher rate of toxicity with the $500 \mathrm{mg}$ daily dose and the similar response rates for the two doses. In contrast, the BR.21 trial investigated erlotinib at the MTD (maximum tolerated dose). It is possible that cases that had limited sensitivity or were partially dependent on the EGFR pathway may have had a greater clinical benefit from the MTD dose of erlotinib than gefitinib, which was given at approximately $40 \%$ of the MTD. There has also been extensive investigation into molecular markers that explain the significant difference in clinical outcomes associated with EGFR-TKI therapy. A difference in the prevalence of one 
Table I Results of the ISEL trial|28,31

\begin{tabular}{|c|c|c|c|c|c|c|c|c|c|}
\hline & $\begin{array}{l}\text { Number of } \\
\text { patients }\end{array}$ & $\begin{array}{l}\mathbf{R R} \\
\text { (\%) }\end{array}$ & $\mathbf{P}$ & $\begin{array}{l}\text { TTF } \\
\text { (months) }\end{array}$ & $\begin{array}{l}\text { HR } \\
{[95 \% \mathrm{Cl}]}\end{array}$ & $\boldsymbol{P}$ & $\begin{array}{l}\text { OS } \\
\text { (months) }\end{array}$ & $\begin{array}{l}\text { HR } \\
{[95 \% \mathrm{Cl}]}\end{array}$ & $P$ \\
\hline \multicolumn{10}{|c|}{ Results in overall population $(n=1,692)$} \\
\hline Gefitinib $250 \mathrm{mg}$ & 1129 & 8.0 & \multirow{2}{*}{$<0.0001$} & 3.0 & 0.82 & \multirow{2}{*}{0.0006} & 5.6 & 0.89 & \multirow{2}{*}{0.087} \\
\hline Placebo & 563 & 1.3 & & 2.6 & {$[0.73-0.92]$} & & 5.1 & {$[0.77-1.02]$} & \\
\hline \multicolumn{10}{|c|}{ Results in adenocarcinoma subtype population $(n=8 \mid 2)$} \\
\hline Gefitinib $250 \mathrm{mg}$ & 541 & 11.9 & 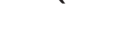 & - & - & \multirow{2}{*}{-} & 6.3 & 0.84 & \multirow{2}{*}{0.089} \\
\hline Placebo & 271 & - & - & - & - & & 5.4 & {$[0.68-1.03]$} & \\
\hline \multicolumn{10}{|c|}{ Results in never-smoker subgroup population $(n=375)$} \\
\hline Gefitinib $250 \mathrm{mg}$ & 250 & 18.1 & \multirow[b]{2}{*}{-} & 5.6 & 0.55 & \multirow{2}{*}{$<0.0001$} & 8.9 & 0.67 & \multirow{2}{*}{0.012} \\
\hline Placebo & 125 & - & & 2.8 & {$[0.42-0.72]$} & & 6.1 & {$[0.49-0.92]$} & \\
\hline \multicolumn{10}{|c|}{ Results in Asian subgroup population $(n=342)$} \\
\hline Gefitinib $250 \mathrm{mg}$ & 235 & 12.4 & \multirow{2}{*}{-} & 4.4 & 0.69 & \multirow{2}{*}{0.0084} & 9.5 & 0.66 & \multirow{2}{*}{0.010} \\
\hline Placebo & 107 & 2.1 & & 2.2 & {$[0.52-0.91]$} & & 5.5 & {$[0.48-0.91]$} & \\
\hline \multicolumn{10}{|c|}{ Results in patients with high EGFR gene copy number $(n=1 \mid 4)$} \\
\hline Gefitinib $250 \mathrm{mg}$ & 235 & 16.4 & \multirow{2}{*}{-} & 4.5 & 0.55 & \multirow{2}{*}{-} & 8.3 & 0.61 & \multirow{2}{*}{0.067} \\
\hline Placebo & 107 & 3 & & 1.9 & {$[0.34-0.89]$} & & 4.5 & {$[0.36-1.04]$} & \\
\hline \multicolumn{10}{|c|}{ Results in patients with low EGFR gene copy number $(n=256)$} \\
\hline Gefitinib $250 \mathrm{mg}$ & 235 & 3.2 & \multirow{2}{*}{-} & 2.4 & 1.25 & \multirow{2}{*}{-} & 4.3 & 1.16 & \multirow{2}{*}{0.417} \\
\hline Placebo & 107 & 0 & & 3.9 & {$[0.92-1.72]$} & & 6.2 & {$[0.8 \mathrm{I}-1.64]$} & \\
\hline \multicolumn{10}{|c|}{ Results in patients with EGFR protein expression positive $(n=264)$} \\
\hline Gefitinib $250 \mathrm{mg}$ & 235 & 8.2 & \multirow{2}{*}{-} & 2.8 & 0.83 & \multirow[b]{2}{*}{-} & 5.5 & 0.77 & \multirow{2}{*}{0.126} \\
\hline Placebo & 107 & 1.5 & & 3.2 & {$[0.61-1.12]$} & & 4.6 & {$[0.56-1.08]$} & \\
\hline \multicolumn{10}{|c|}{ Results in patients with EGFR protein expression negative $(n=|| 5)$} \\
\hline Gefitinib $250 \mathrm{mg}$ & 235 & 1.5 & \multirow{2}{*}{-} & 1.9 & 1.24 & \multirow[b]{2}{*}{-} & 4.2 & 1.57 & \multirow{2}{*}{0.140} \\
\hline Placebo & 107 & 0 & & 3.9 & [0.77-2.02] & & NR & [0.86-2.87] & \\
\hline
\end{tabular}

Abbreviations: RR, response rate; TTF, time to treatment failure; HR, hazard ratio; Cl, confidence interval; OS, overall survival; NR, not reached; -, data not available.

or more of the biomarkers associated with the response or resistance to EGFR-TKI therapy between the two trials may have contributed to the difference in the results.

A biological ISEL sub-study was performed including the assessment of EGFR gene copy number by fluorescent in situ hybridization (FISH), EGFR and p-AKT protein expression by immunohistochemistry (IHC), EGFR, K-RAS and $B-R A F$ mutational status (Figure 1). ${ }^{31}$ It showed that a high $E G F R$ gene copy number in patients treated with gefitinib represents a predictive factor of survival benefit when compared with placebo (HR: 0.61 versus 1.16 for high and low gene copy number, respectively; interaction test, $P=0.045)$, such as EGFR expression (HR: 0.77 versus 1.57 for positive and negative protein expression, respectively; interaction test, $P=0.049$ ) (Table 1). Data on survival from the ISEL trial are consistent with the results from biological sub-study of BR. 21 trial. ${ }^{32,33}$

In addition, patients with $E G F R$ mutations obtained higher RR than wild-type patients (37.5\% versus $2.6 \%$ ). According to p-AKT, no correlation was observed in terms of survival; although there was a better RR in p-AKT positive patients treated with gefitinib when compared to $\mathrm{p}$-AKT negative ones (10.1\% versus $6.3 \%$, respectively). Of 12 patients with a $K-R A S$ mutation, 6 were treated with gefitinib and no responses were seen, whereas no $B-R A F$ mutations were detected.

\section{Gefitinib versus chemotherapy Phase II study: SIGN (second line indication of gefitinib in NSCLC) trial}

The SIGN was a phase II open-label randomized study, comparing gefitinib $250 \mathrm{mg} /$ day $(\mathrm{n}=60$ patients $)$ with docetaxel $75 \mathrm{mg} / \mathrm{m}^{2}$ every 3 weeks ( $\mathrm{n}=73$ patients) in advanced pretreated NSCLC. ${ }^{34}$ The trial was not designed to test for a statistical difference between treatments on any endpoint its primary objective was symptom improvement using the FACT-L questionnaire (see below "Quality of life"). The results suggest that gefitinib and docetaxel have similar activity and efficacy; (symptom improvement rates of $36.8 \%$ and $26 \%$; RR of $13.2 \%$ and $13.7 \%$; median PFS of 3 and 3.4 months; median OS of 7.5 and 7.1 months, with quality of life improvement rates of $33.8 \%$ and $26 \%$, for gefitinib and docetaxel, respectively), with a more favorable tolerability profile for gefitinib (adverse events of all grades: $51.5 \%$ and $78.9 \%$, of grade $3-4$ $8.8 \%$ and $25.4 \%$ ) 


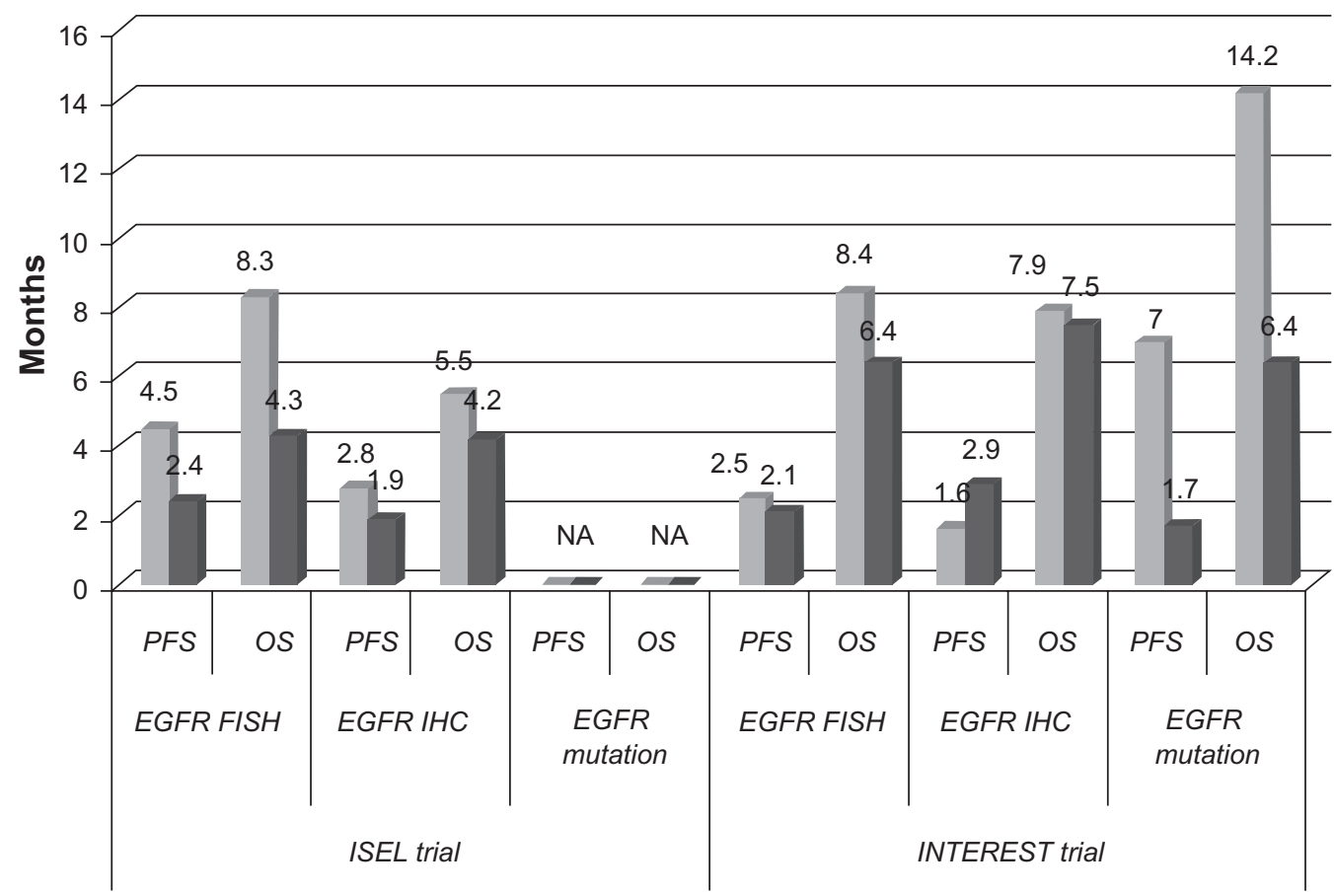

positive

negative

Figure I Progression-free survival (PFS) and overall survival (OS) results (months) obtained with gefitinib in EGFR biomarker subgroups of ISEL and INTEREST trials. . $^{31,38}$ Abbreviations: PFS, progression-free survival; OS, overall survival; NA, not available; IHC, immunohistochemistry; EGFR FISH positive, high gene copy number; EGFR FISH negative, low gene copy number.

\section{Phase III studies: INTEREST,V-I5-32 and ISTANA trials}

Recently, the results of three phase III trials comparing gefitinib versus docetaxel in this setting have been published (Table 2). ${ }^{35-37}$

\section{INTEREST (Iressa NSCLC trial evaluating} response and survival versus taxotere) trial

The INTEREST trial compared gefitinib with docetaxel as second- or third-line therapy in 1,466 patients with advanced NSCLC treated with prior platinum-based chemotherapy. ${ }^{35}$ The patients were randomly assigned on a 1:1 basis to receive either gefitinib $250 \mathrm{mg} /$ day or docetaxel $75 \mathrm{mg} / \mathrm{m}^{2}$ every 3 weeks. The primary endpoints were the non-inferiority of gefitinib in comparison with docetaxel, in terms of overall survival in the total population and superiority in patients who expressed a high EGFR gene copy number.

In the overall population, median OS was 7.6 months in the gefitinib group versus 8.0 months in the docetaxel group, with a 1 -year survival of $32 \%$ versus $34 \%$, respectively, demonstrating the non-inferiority of gefitinib with respect to docetaxel (HR, 1.020, 95\% CI, 0.905-1.150, with the upper confidence limit less than the non-inferiority limit of 1.154)

Table 2 Phase III trials of gefitinib versus chemotherapy as second-line treatment

\begin{tabular}{|c|c|c|c|c|c|c|c|c|c|}
\hline & $\begin{array}{l}\text { Number of } \\
\text { patients }\end{array}$ & $\begin{array}{l}\mathbf{R R} \\
\text { (\%) }\end{array}$ & $P$ & $\begin{array}{l}\text { PFS } \\
\text { (months) }\end{array}$ & $\begin{array}{l}\text { HR } \\
{[95 \% \mathrm{Cl}]}\end{array}$ & $P$ & $\begin{array}{l}\text { OS } \\
\text { (months) }\end{array}$ & $\begin{array}{l}\text { HR } \\
{[95 \% \mathrm{Cl}]}\end{array}$ & $P$ \\
\hline \multicolumn{10}{|c|}{ INTEREST trial $(n=I, 433)^{35}$} \\
\hline Gefitinib $250 \mathrm{mg}$ & 733 & 9.1 & \multirow{2}{*}{0.33} & 2.2 & 1.04 & \multirow{2}{*}{0.47} & 7.6 & 1.020 & \multirow{2}{*}{-} \\
\hline Docetaxel 75 mg/m² & 733 & 7.6 & & 2.7 & {$[0.93-1.18]$} & & 8.0 & {$[0.905-1.150]$} & \\
\hline \multicolumn{10}{|c|}{ V-I5-32 trial $(n=489)^{36}$} \\
\hline Gefitinib $250 \mathrm{mg}$ & 245 & 22.5 & \multirow{2}{*}{0.009} & 2.0 & 0.81 & \multirow{2}{*}{0.77} & 11.5 & 1.12 & \multirow{2}{*}{0.330} \\
\hline Docetaxel $60 \mathrm{mg} / \mathrm{m}^{2}$ & 244 & 12.8 & & 2.0 & {$[0.65-1.02]$} & & 14.0 & {$[0.89-1.40]^{*}$} & \\
\hline \multicolumn{10}{|c|}{ ISTANA trial $(n=161)^{37}$} \\
\hline Gefitinib $250 \mathrm{mg}$ & 82 & 28.1 & \multirow{2}{*}{0.0007} & 3.3 & 0.729 & \multirow{2}{*}{0.0441} & 14.1 & 0.870 & \multirow{2}{*}{0.437} \\
\hline Docetaxel $60 \mathrm{mg} / \mathrm{m}^{2}$ & 79 & 7.6 & & 3.4 & {$[0.533-0.998]^{* *}$} & & 12.2 & {$[0.613-1.236]$} & \\
\hline
\end{tabular}

Notes: $* 95.24 \% \mathrm{Cl}$. $* * 90 \% \mathrm{Cl}$.

Abbreviations: RR, response rate; TTF, time to treatment failure; $\mathrm{HR}$, hazard ratio; $\mathrm{Cl}$, confidence interval; OS, overall survival; $\mathrm{NR}$, not reached; -, data not available; PFS, progression-free survival. 
(Table 2). Nevertheless, the survival superiority of gefitinib in the subgroup with high EGFR gene copy number was not proven (8.4 versus 7.5 months; HR, 1.09, 95\% CI, 0.78-1.51, $P=0.62)$. Survival results were consistent across preplanned subgroups.

The median PFS and RR were similar in both treatment groups (Table 2), although gefitinib afforded a statistically significant higher rate of improvement in quality of life (see below "Quality of life").

Moreover, gefitinib had a better tolerability profile; the most common gefitinib adverse events were skin reactions and diarrhea, whereas hematologic disorders (neutropenia grade 3-4 and febrile neutropenia), asthenia and alopecia were more likely to occur with docetaxel.

Recently, the results of a preplanned analysis of molecular predictors from the INTEREST trial have been published. ${ }^{38}$ The biomarkers considered were $E G F R$ gene copy number by FISH, EGFR protein expression by IHC, EGFR and $K-R A S$ mutational status (Figure 1). Data obtained showed no statistically significant impact of these biomarkers in terms of OS. EGFR mutation positive patients had longer PFS (HR, $0.16,95 \% \mathrm{CI}, 0.05-0.49, P=0.001)$ and higher RR $(42.1 \%$ versus $21.1 \%, P=0.04$ ) and patients with high $E G F R$ copy number had higher RR (13\% versus $7.4 \%, P=0.04)$ with gefitinib versus docetaxel. These biomarkers do not appear to be factors for differential survival between gefitinib and docetaxel in this setting; however, subsequent treatments may have influenced the survival results. There was no statistically significant difference between gefitinib and docetaxel in biomarker-negative patients. This suggests that gefitinib can provide similar overall survival to docetaxel in patients across a broad range of clinical subgroups and that EGFR biomarkers such as mutation status may additionally identify which patients are likely to gain the greatest PFS and RR benefit from gefitinib.

\section{V-I5-32 trial}

This phase III study compared gefitinib $250 \mathrm{mg} /$ day with docetaxel $60 \mathrm{mg} / \mathrm{m}^{2}$ every 3 weeks in 489 Japanese patients with advanced NSCLC, who were treated with one or two prior chemotherapy regimens. ${ }^{36}$ Of the 489 patients enrolled, approximately $78 \%$ had adenocarcinoma histology, $38 \%$ were female and $32 \%$ were never-smokers.

The primary endpoint was the non-inferiority of gefitinib in comparison with docetaxel in overall survival; the upper limit of the CI was required to be $\leq 1.25$ in order to demonstrate non-inferiority. This trial demonstrated similar efficacy between gefitinib and docetaxel; however, it did not meet the primary endpoint of demonstrating non-inferiority (HR, 1.12, 95.24\% CI, 0.89-1.40, $P=0.330$ ) (Table 2). This result could be due to the small number of patients and to post-study cross-over ( $36 \%$ of patients treated with gefitinib received subsequent docetaxel and $53 \%$ of docetaxel treated patients received subsequent gefitinib). In addition, the median PFS was 2.0 months in both treatment groups, whereas gefitinib was statistically superior to docetaxel in terms of RR (Table 2). Gefitinib also significantly improved the quality of life as compared to docetaxel. The disease control rates and symptom improvement were similar for the two treatments. Gefitinib was also better tolerated than docetaxel (see below "Safety and tolerability").

\section{ISTANA (IRESSA as second-line therapy in advanced NSCLC) trial}

This was a phase III trial conducted in Korea that compared gefitinib with docetaxel as a second-line treatment in 161 patients with advanced NSCLC. ${ }^{37}$ Its primary endpoint was PFS.

PFS was found to be longer on gefitinib when compared with docetaxel; the PFS HR for gefitinib derived from the primary unadjusted model was 0.729 (90\% CI, $0.533-0.988$, one-sided $P=0.0441$ ) and from the supportive adjusted model was 0.634 (90\% CI, 0.459-0.875, one-sided $P=0.0134)$. Median PFS was 3.3 months in the gefitinib group and 3.4 months in the docetaxel group; the 6-month PFS rates were $32 \%$ and $13 \%$, respectively. In terms of RR, gefitinib was statistically superior to docetaxel (Table 2). In the final analysis of OS, the HR was $0.870(95 \% \mathrm{CI}$, $0.613-1.236, P=0.437)$. No significant differences were seen in the quality of life or symptom improvement rates between the two treatment groups. Gefitinib was well tolerated, was consistent with previous data and had fewer adverse events than docetaxel.

Therefore, gefitinib showed in this trial an advantage over docetaxel in terms of PFS and RR as a second-line treatment; however, it is necessary underline its limited sample size, smaller than other similar studies, and the patient selection (only Korean or Asian ethnicity patients with a high proportion of never smokers and patients with adenocarcinoma histology).

\section{Gefitinib versus docetaxel: a meta-analysis of four clinical trials}

At the last American Society of Clinical Oncology (ASCO) Annual Meeting, Shepherd and colleagues presented a meta-analysis of the four previously reported randomized 
trials, evaluating gefitinib versus docetaxel in unselected pretreated patients with advanced NSCLC (SIGN, INTEREST, V-15-32, and ISTANA trials). ${ }^{39}$ In this meta-analysis gefitinib showed similar OS (HR, 1.03, 95\% CI, 0.93-1.13, $P=0.5773$ ) and PFS (HR, 0.96, 95\% CI, 0.87-1.05, $P=0.3784$ ), with a statistically significant increase in the RR (13.6\% versus 9\%, OR, 1.65, 95\% CI, 1.24-2.21, $P=0.0007$ ) when compared with docetaxel. This meta-analysis adds to the weight of evidence that gefitinib and docetaxel show similar efficacy in pretreated patients with advanced NSCLC and further contributes to defining the risk-benefit profile of each treatment, which also considers tolerability and ease of administration.

\section{Gefitinib as first-line therapy Gefitinib in combination with chemotherapy: the failing experience of INTACT-I and INTACT-2 trials}

The results obtained with gefitinib as a single agent in IDEAL trials $^{26,27}$ led some authors to test the drug in association with chemotherapy as front-line treatment in two randomized phase III trials, INTACT-1 and INTACT-2 (Iressa NSCLC Trial Assessing Combination Treatment). ${ }^{40,41}$

The rationale to test the efficacy of the gefitinibchemotherapy association was given by evidence, in preclinical studies, of interaction between gefitinib and cytotoxic drugs (in particular with cisplatin); ie, a different mechanism of action and favorable safety profile of gefitinib. ${ }^{42}$

Unfortunately, both studies failed to demonstrate a survival advantage when gefitinib was associated with chemotherapy (Table 3). INTACT-1 was a three arm trial in which 1,093 patients were randomized to receive cisplatin and gemcitabine for 6 cycles plus gefitinib $500 \mathrm{mg} /$ day, $250 \mathrm{mg} /$ day or placebo. ${ }^{40}$ Gefitinib was continued after chemotherapy until progression or unacceptable toxicity. Most of the patients were enrolled in European (74\%) and North American (12\%) centers. The primary endpoint was overall survival. The results were quite disappointing; the gefitinib arms showed no differences in OS as compared with the placebo arm. No differences were observed for the time to progression (TTP) and RR (Table 3). Subgroup analysis for sex, histology and time on chemotherapy also did not show any survival difference.

INTACT-2 was a three arms trial in which 1,037 patients, mostly in the US, were randomized to receive carboplatin and paclitaxel for 6 cycles plus gefitinib $500 \mathrm{mg} /$ day, $250 \mathrm{mg} /$ day or placebo. ${ }^{41}$ As in previous study the primary endpoint was OS. The results of this trial did not show any differences from those of INTACT-1 trial (Table 3). The subgroup analysis did not show any statistical difference in survival except for a slight trend toward improved survival for patients with adenocarcinoma; these patients received chemotherapy for more than 90 days in the gefitinib $250 \mathrm{mg}$ /day arm, suggesting a possible effect of gefitinib monotherapy as maintenance therapy. However, this result was not observed in INTACT-1 study.

Two similar phase III trials assessing the efficacy of erlotinib in association with chemotherapy (TRIBUTE and TALENT trials) were conducted at the same time as the INTACT studies and showed similar results, confirming the absence of any benefit in the addition of TKIs to chemotherapy as first-line treatment of advanced NSCLC. ${ }^{43,44}$

The two gefitinib trials, INTACT 1 and 2, were well designed, adequately powered, and well conducted. The conclusion that concomitant gefitinib administration does not add clinical benefit to conventional chemotherapy in NSCLC seems, therefore, irrefutable. Different theories have been formulated to explain this lack of efficacy. One hypothesis is that each agent works against the same cell subpopulation

Table 3 Phase III trials of gefitinib in combination with chemotherapy as first-line treatment of advanced NSCLC (INTACT-I and 2)

\begin{tabular}{|c|c|c|c|c|c|c|c|}
\hline & Number of patients & $\mathbf{R R}(\%)$ & $\boldsymbol{P}$ & TTP (months) & $P$ & OS (months) & $P$ \\
\hline \multicolumn{8}{|c|}{ INTACT-I trial $(\mathrm{n}=1,093)^{40}$} \\
\hline GP + Gefitinib 500 mg & 365 & 50.3 & & 5.5 & & 9.9 & \\
\hline $\mathrm{GP}+$ Gefitinib $250 \mathrm{mg}$ & 365 & 51.2 & - & 5.8 & 0.76 & 9.9 & 0.45 \\
\hline GP + Placebo & 363 & 47.2 & & 6.0 & & 10.9 & \\
\hline \multicolumn{8}{|c|}{ INTACT-2 trial $(n=1,037)^{41}$} \\
\hline PC + Gefitinib $500 \mathrm{mg}$ & 347 & 30.0 & & 4.6 & & 8.7 & \\
\hline$P C+$ Gefitinib $250 \mathrm{mg}$ & 345 & 30.4 & - & 5.3 & 0.056 & 9.8 & 0.64 \\
\hline PC + Placebo & 345 & 28.7 & & 5.0 & & 9.9 & \\
\hline
\end{tabular}

Notes: In INTACT-I trial: G, gemcitabine $1250 \mathrm{mg} / \mathrm{m}^{2} \mathrm{dI}, 8$ and $P$, cisplatin $80 \mathrm{mg} / \mathrm{m}^{2} \mathrm{dl}$ every 3 weeks; gefitinib or placebo were administered daily in association with chemotherapy up to 6 cycles then alone until disease progression. In INTACT-2 trial: $P$, paclitaxel $225 \mathrm{mg} / \mathrm{m}^{2} \mathrm{dI}$ and C, carboplatin AUC $6 \mathrm{dI}$ every 3 weeks; gefitinib or placebo were administered daily in association with chemotherapy up to 6 cycles then alone until disease progression.

Abbreviations: RR, response rate; TTP, time to progression; OS, overall survival; -, data not available. 
so that the effect is redundant. Another hypothesis is that the activity of one agent results in the loss of an intermediary molecule, which is essential to the function of the other agent. At present, the strongest hypothesis about the failure of the two studies seems to be that the patients were not selected for any of the known criteria that has later been discovered to be associated with a sensitivity to gefitinib, so that the population who was most likely to receive a real benefit from the agent (EGFR mutation) did not amount enough to statistically change the results obtained.

\section{Gefitinib in elderly and poor-performance patients: INVITE and INSTEP trials}

Considering its good toxicity profile, gefitinib has recently been tested as an alternative to single agent monotherapy in elderly and poor performance status (PS) NSCLC patients.

INVITE (IRESSA in NSCLC versus Vinorelbine Investigation in the Elderly) trial is the first phase II study designed to test gefitinib in untreated elderly NSCLC patients compared with a single agent, vinorelbine. ${ }^{45}$ In this study 196 unselected patients aged $>70$ years were randomly assigned to receive gefitinib $250 \mathrm{mg} /$ day until progression or vinorelbine for up to 6 cycles. The primary endpoint was PFS; this trial was designed to determine the superiority of gefitinib as compared with vinorelbine. The results showed no statistical difference in PFS (2.7 versus 2.9 months, HR 1.19, 95\% CI, $0.85-1.65, P=0.310)$, OS (5.9 versus 8.0 months; HR 0.98 , 95\% CI, 0.66-1.47), RR (3.1\% versus 5.1\%) and disease control rates (43.3\% versus $53.5 \%$ ) for gefitinib and vinorelbine, respectively. Overall, the quality of life improvement and pulmonary symptom improvement rates were in favor of gefitinib. As expected, gefitinib showed better tolerability profile than vinorelbine.

Although the present study was not designed to show equivalence between the two drugs, there was no statistical difference between the two treatments, suggesting that gefitinib could represent an alternative to single-agent chemotherapy in elderly patients. It is important to underline that the totality of the population enrolled in this trial was unselected for the features that confer sensitivity to gefitinib; in fact, most of them were male (77\%), smokers (82\%) and with squamous cell carcinoma (48\%) and this might explain the low percentage of responders. Most patients were analyzed for $E G F R$ gene copy number by FISH; surprisingly, the 54 patients who were EGFR FISH positive benefited more from vinorelbine than from gefitinib (HR, 3.13, 95\% CI, 1.45-6.76 for PFS and HR, 2.88, 95\% CI, 1.21-6.83 for OS). This finding was unexpected and in contrast to previous observations.
The INSTEP (IRESSA NSCLC Trial Evaluating Poor PS Patients) trial was a phase II study, comparing gefitinib to $\mathrm{BSC}$ in untreated patients with $\mathrm{PS} \geq 2$, not eligible for chemotherapy. ${ }^{46}$ In this study, 201 patients were randomized to receive gefitinib $250 \mathrm{mg} /$ day until progression or unacceptable toxicity or BSC. Primary endpoint was PFS. The results showed no statistical difference in outcome for patients treated with gefitinib, even though there was a small trend toward improved PFS, OS and RR in favor of gefitinib. HRs were 0.82 (95\% CI, 0.60-1.12, $P=0.217)$ and $0.84(95 \%$ CI, 0.62-1.15, $P=0.272$ ), for PFS and OS, respectively. RR was $6 \%$ for gefitinib and $1 \%$ for placebo. No statistical difference was seen in the quality of life. In the subgroup of EGFR FISH positive patients $(\mathrm{n}=32)$, gefitinib improved significantly PFS (HR, 0.29) and there was a trend toward an increase in OS. This trial failed to demonstrate a statistically significant benefit for first-line gefitinib compared with BSC in unfit patients; however, a number of reports from gefitinib expanded access program (EAP) suggest that gefitinib may have utility as first-line treatment in patients with poor PS or unwilling to receive chemotherapy. ${ }^{47}$

\section{Gefitinib in selected patients}

As indicated above, gefitinib, when used in unselected patients, allows only a modest response rate ranging from $10 \%$ up to $20 \%$. Nevertheless, it appears that a higher benefit can be obtained in some patient subgroups, such as females, never smokers, Asians and patients with adenocarcinoma histology. Although clinical characteristics may identify candidates for EGFR-TKIs, the ideal patient selection should mostly rely on biological tumor features, in particular in the presence of EGFR gene mutations. The most common mutations are exon 19 deletions and exon 21 point mutation (L858R), which can be found in approximately $10 \%-20 \%$ of NSCLC patients, more frequently in never smokers, women, Asians and with adenocarcinoma. ${ }^{48-50}$ These alterations in structure of the self-phosphorylating domain enhance EGFR activation and also favor binding of TKIs to their site of action. Patients who harbor these mutations experience response rates higher than $65 \%$ and median survival of 20-30 months, as demonstrated in several retrospective studies. ${ }^{51-55}$ Such results led investigators to test gefitinib as a first-line therapy in EGFR mutated patients in prospective trials.

\section{Phase II studies}

Several phase II trials investigated the efficacy of gefitinib as a first-line treatment in highly selected patient 
populations, based on the presence of activating EGFR gene mutations. ${ }^{56-60}$

In a phase II trial, Asahina and colleagues obtained a RR of $75 \%$ and median PFS of 8.9 months. ${ }^{56}$ Inoue and colleagues evidenced similar results in 16 patients with $E G F R$ mutated, identified among 75 chemonaive patients (RR of $75 \%$, with a DCR of $88 \%$ and a median PFS time of 9.7). ${ }^{57}$ Yang and colleagues enrolled 106 patients selected by clinical features and determined their EGFR mutation status in 90 of these patients. Exon 19 deletions and L858R mutations were present in 43 patients; the RR and median time to treatment failure were $95 \%$ and 8.9 months, respectively, for exon 19 deletions, and $73.9 \%$ and 9.1 months for L858R mutation. ${ }^{58}$

Similar results were obtained also in Caucasian patients. Sequist and colleagues (the iTARGET trial) selected chemonaive patients with non-squamous histology who had one or more clinical characteristics associated with activating EGFR mutations (low or never smoking history, adenocarcinoma histology, female gender and East Asian ethnicity).$^{59}$ In this clinically enriched patient population, mutations were identified in $35 \%$ of patients, which is higher than the rate of $10 \%-15 \%$ seen in previous studies of Western populations. ${ }^{58}$ Thirty-one patients received gefitinib: RR was 55\%, median PFS was 9.2 months, OS 17.5 months, with 1 -year survival of $73 \%$. Two patients with classic activating mutations exhibited de novo gefitinib resistance and had concurrent genetic anomalies usually associated with acquired TKI resistance, specifically the T790M EGFR mutation and MET amplification. This study has demonstrated that genotype-directed EGFR-TKI therapy with gefitinib for patients with previously untreated NSCLC is feasible in a Western population.

Considering the favorable safety profile, Inoue and colleagues tested gefitinib in a phase II trial in NSCLC patients with poor PS harboring EGFR mutations, not eligible for chemotherapy. ${ }^{60}$ Thirty patients with NSCLC and poor PS, including 22 patients with PS 3 to 4, were enrolled. The overall RR was $66 \%$, with a DCR of $90 \%$. PS improvement rate was $79 \%$. The median PFS and OS were 6.5 and 17.8 months, respectively. Despite the fact that most of these patients had aggressive disease, treatment with gefitinib in this setting yielded a median survival three- to four-fold higher than that generally observed with conventional cytotoxics. This is the first report indicating that EGFR mutation-positive patients with extremely poor PS benefit from first-line gefitinib. Because there has previously been no standard treatment for these patients with short-life expectancy, other than BSC, examination of $E G F R$ mutations as a biomarker should be recommended in this patient population.

All these studies demonstrated an advantage in the use of gefitinib as first-line therapy in selected patients harboring EGFR activating mutations, achieving outcome results, which are higher than any other treatment used in NSCLC. Other prospective trials showed similar results in EGFR mutated NSCLC populations in further lines of treatment. ${ }^{61-65}$

Additional trials have selected patients based on a combination of clinical, pathological or molecular features. The ONCOBELL trial selected patients who were never smokers or who had evidence of a high gene copy on FISH and were p-AKT positive. ${ }^{66}$ Of the 183 patients who were evaluated, 42 patients were enrolled in the trial and treated with gefitinib. The RR observed was $47.6 \%$, the median TTP was 6.4 months and the 1-year survival rate was $64.3 \%$. EGFR mutations were detected in 24 patients $(66.8 \%)$ and the RR observed in those patients was $62.5 \%$. The Southwest Oncology Group performed a phase II trial for patients with bronchioalveolar carcinoma. ${ }^{67}$ This trial included previously treated $(n=22)$ and untreated $(n=69)$ patients that received gefitinib at a dose of $500 \mathrm{mg}$ daily. The RR in the previously treated and untreated patients was $9 \%$ and $17 \%$, respectively, and the PFS times were 3 and 4 months, respectively. Another area of investigation is the selection of patients based on the clinical history of non-smoking. A phase II trial investigated the activity of gefitinib (250 mg daily) in 37 chemotherapy-naive Korean patients with adenocarcinoma histology and a never smoking history. ${ }^{68}$ The observed RR was $69 \%$, with a DCR of $81 \%$. The median PFS time and 1-year survival rate observed were 33 weeks and $73 \%$, respectively.

\section{Phase III studies: IPASS, First-SIGNAL, WJTOG3405 and NEJ002 trials}

According to the results obtained with gefitinib as a first-line treatment in phase II trials performed in selected populations, four Asian randomized phase III trials (IPASS, FirstSIGNAL, WJTOG3405 and NEJ002) were conducted to assess whether gefitinib could represent a valid alternative to chemotherapy in this setting of disease. ${ }^{69-72}$

\section{IPASS (Iressa Pan-Asia Study) trial}

The IPASS trial was a randomized phase III study where previously untreated patients in East Asia who had advanced pulmonary adenocarcinoma and who were non-smokers or former light smokers were randomized to receive gefitinib or carboplatin-paclitaxel. ${ }^{69}$ 
Eligible patients were chemotherapy-naive with NSCLC with adenocarcinoma histology, never $(<100$ cigarettes in lifetime) or light ex-smokers (stopped $\geq 15$ years ago and smoked $\leq 10$ pack years) and with a performance status of 0 to 2 . A total of 1,217 patients were randomized to receive either gefitinib (250 mg/day; $\mathrm{n}=609)$ until disease progression or other criteria for discontinuation or carboplatin (AUC 5 or 6$)$ and paclitaxel $\left(200 \mathrm{mg} / \mathrm{m}^{2}\right.$ every 3 weeks $)(\mathrm{n}=608)$ for a maximum of 6 cycles or until disease progression or other criteria for discontinuation.

The primary objective was to assess the non-inferiority of gefitinib versus carboplatin-paclitaxel for PFS. Exploratory objectives were to evaluate the efficacy outcomes in biomarker subgroups defined by EGFR mutation status, EGFR gene copy number by FISH and EGFR IHC expression.

The study exceeded the primary objective and demonstrated superiority of gefitinib relative to carboplatinpaclitaxel in terms of PFS in the intent-to-treat population (Table 4). The HR was 0.74 (95\% CI, 0.65-0.85, $P<0.001)$. Median PFS was 5.7 versus 5.8 months in gefitinib and chemotherapy group, respectively, with 12-month rates of PFS of $24.9 \%$ versus $6.7 \%$. Therefore, the risk of progression was reduced by $26 \%$ on gefitinib compared with carboplatinpaclitaxel; however, the hazard ratio was not constant over time. Because of the crossing of the curves, the median PFS is similar on both treatments, although clearly it is not a good reflection of the treatment effect in this study. In fact, the pattern of the 4, 6 and 12-month progression-free rates favor carboplatin-paclitaxel for the first 6 months and gefitinib for the remaining 16 months. The PFS treatment effect was consistent with the overall population in all clinical subgroups.
At the time of data cut-off, for the primary analysis (14 April 2008), the data were immature as there were only $450 / 1217$ deaths (37\%). Follow-up for survival is ongoing. OS was similar between the gefitinib and carboplatinpaclitaxel arms and may be influenced by the large amount of subsequent therapy received in this study, making these data difficult to interpret. Objective RR was significantly higher with gefitinib (43.0\%) than with carboplatin-paclitaxel (32.2\%) (OR, 1.59, 95\% CI, 1.25-2.01, $P<0.001)$.

Another important finding of the study was the result obtained in the subgroup of patients that were positive for EGFR mutation. In IPASS, 261 patients $(59.7 \%$ of those with a known status) were mutation positive, the largest group ever studied in a randomized controlled trial of an EGFRTKI to date, reflecting the clinical selection of the patients in this study (Figure 2). Some striking differences in PFS outcome by $E G F R$ mutation status were seen (interaction test, $P<0.0001)$. PFS was significantly longer for gefitinib than carboplatin-paclitaxel in mutation positive patients (HR, 0.48, 95\% CI, 0.36-0.64, $P<0.001$ ), while it was significantly longer for chemotherapy in mutation negative patients (HR, 2.85, 95\% CI, 2.05-3.98, $P<0.001)$. Within these subgroups, the treatment effect appears to be constant over time, unlike in the overall study population. Among the EGFR mutation negative patients, over half of those receiving gefitinib had progressed by the time of the first scheduled scan at 6 weeks and this is likely to be driving the initial disadvantage for gefitinib in the overall population curves, with the later advantage being driven by the very long PFS for gefitinib in EGFR mutation positive patients. The EGFR mutation positive benefit outweighs the EGFR

Table 4 Phase III trials of gefitinib versus chemotherapy as first-line treatment in clinically selected patients

\begin{tabular}{|c|c|c|c|c|c|c|c|c|c|}
\hline & $\begin{array}{l}\text { Number of } \\
\text { patients }\end{array}$ & $\begin{array}{l}\mathbf{R R} \\
\text { (\%) }\end{array}$ & $P$ & $\begin{array}{l}\text { PFS } \\
\text { (months) }\end{array}$ & $\begin{array}{l}\text { HR } \\
{[95 \% \mathrm{Cl}]}\end{array}$ & $\mathbf{P}$ & $\begin{array}{l}\text { OS } \\
\text { (months) }\end{array}$ & $\begin{array}{l}\text { HR } \\
{[95 \% \mathrm{Cl}]}\end{array}$ & $P$ \\
\hline \multicolumn{10}{|c|}{ IPASS trial $(n=1,217)^{69}$} \\
\hline Gefitinib & 609 & 43 & \multirow{2}{*}{$<0.001$} & 5.7 & 0.74 & \multirow{2}{*}{$<0.001$} & 18.6 & 0.91 & \multirow[t]{2}{*}{-} \\
\hline PC & 608 & 32.2 & & 5.8 & {$[0.65-0.85]$} & & 17.3 & {$[0.76-1.10]$} & \\
\hline \multicolumn{10}{|c|}{ Results in EGFR mutation positive patients $(n=261)^{69}$} \\
\hline Gefitinib & 132 & 71.2 & \multirow{2}{*}{$<0.001$} & 9.5 & 0.48 & \multirow{2}{*}{$<0.001$} & - & 0.78 & \multirow[t]{2}{*}{-} \\
\hline PC & 129 & 47.3 & & 6.3 & {$[0.36-0.64]$} & & - & {$[0.50-1.20]$} & \\
\hline \multicolumn{10}{|c|}{ First-SIGNAL trial (309) ${ }^{70}$} \\
\hline Gefitinib & 159 & 53.5 & \multirow{2}{*}{0.153} & 6.1 & 0.813 & \multirow{2}{*}{0.044} & 21.3 & 1.003 & \multirow{2}{*}{0.428} \\
\hline GP & 150 & 45.3 & & 6.6 & {$[0.64|-| .03 \mid]$} & & 23.3 & {$[0.749-1.343]$} & \\
\hline \multicolumn{10}{|c|}{ Results in EGFR mutation positive patients $(42)^{70}$} \\
\hline Gefitinib & 26 & 84.6 & \multirow{2}{*}{0.002} & 8.5 & 0.613 & \multirow{2}{*}{0.084} & 30.6 & 0.823 & \multirow{2}{*}{0.648} \\
\hline GP & 16 & 37.5 & & 6.7 & {$[0.308-1.221]$} & & 26.5 & {$[0.352-1.922]$} & \\
\hline
\end{tabular}

Notes: In IPASS trial: Gefitinib $250 \mathrm{mg} /$ day; P, paclitaxel $200 \mathrm{mg} / \mathrm{m}^{2} \mathrm{dl}$ and C, carboplatin AUC 5 or 6 dI every 3 weeks. In FIRST-SIGNAL trial: Gefitinib 250 mg/day; G, gemcitabine $1250 \mathrm{mg} / \mathrm{m}^{2} \mathrm{dl}, 8$ and $P$, cisplatin $80 \mathrm{mg} / \mathrm{m}^{2} \mathrm{dl}$ every 3 weeks.

Abbreviations: RR, response rate; PFS, progression-free survival; $\mathrm{HR}$, hazard ratio; $\mathrm{Cl}$, confidence interval; OS, overall survival; -, data not available. 


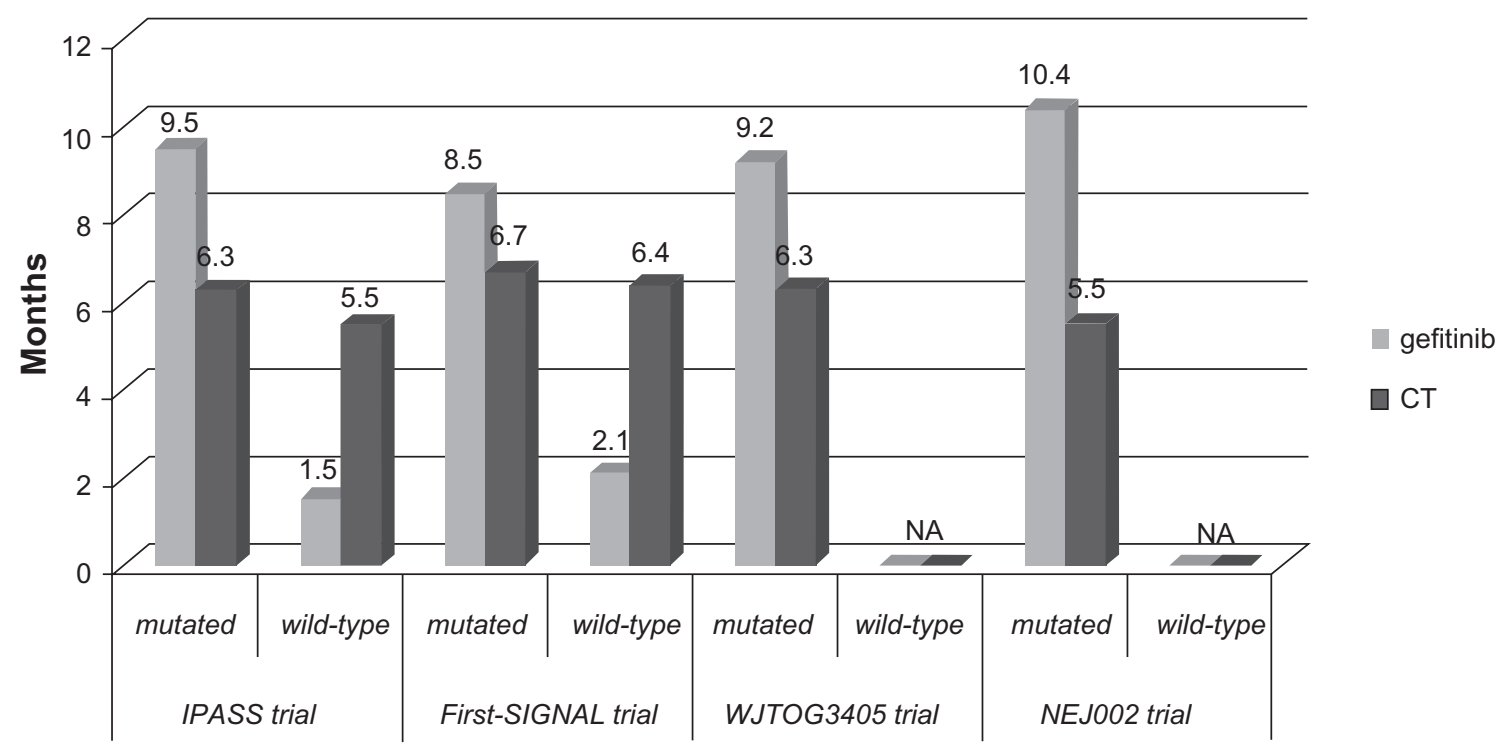

Figure 2 Progression-free survival (PFS) results (months) in EGFR mutated subgroups in IPASS, First-SIGNAL, WJTOG3405 and NEJ002 trials. ${ }^{69-72}$ Abbreviations: NA, not available; EGFR FISH positive, high gene copy number; EGFR FISH negative, low gene copy number.

mutation negative deficit, leading to overall superiority for gefitinib.

A post-hoc analysis of overall survival by mutation status was also performed, acknowledging that there would only be a small number of events in the analysis and hence limited power (only $37 \%$ of patients had died). The hazard ratio was numerically in favor of gefitinib in the $E G F R$ mutation positive patients (based on 81 events; HR, 0.78 , $95 \%$ CI, 0.50-1.20) and numerically in favor of carboplatinpaclitaxel in EGFR mutation negative patients (based on 94 events; HR, 1.38, 95\% CI, 0.92-2.09). However, no statistically significant differences were seen, possibly because the number of events was small.

In the EGFR mutation positive subgroup, RR was significantly higher with gefitinib (71.2\%) than with carboplatin-paclitaxel (47.3\%) $(P<0.001)$, while in the EGFR mutation negative subgroup, RR was significantly higher with carboplatin-paclitaxel (23.5\%) than with gefitinib $(1.1 \%)(P=0.001)$.

About other biomarkers, a possibly related trend was observed with EGFR gene copy number (interaction test, $P=0.0437$ ), with a significant advantage for gefitinib over carboplatin-paclitaxel in patients with high $E G F R$ gene copy number tumors (HR, 0.66, $P=0.005$ ), while in patients with low gene copy number there was a numerical advantage for carboplatin-paclitaxel (HR, 1.24, $P=0.237$ ). Post-hoc analysis suggests this effect was driven by the overlap of high $E G F R$ gene copy number with a positive $E G F R$ mutation status. Objective RR was also significantly higher with gefitinib in the subgroup of patients with high EGFR gene copy number (58.9\% versus $44.8 \% P=0.024)$. In the EGFR expression positive subgroup, objective response rate tended to be higher with gefitinib than with carboplatin-paclitaxel, but the difference was not statistically significant $(51.5 \%$ versus $41.8 \%, P=0.109)$.

Quality of life improvement rates were significantly higher with gefitinib than carboplatin-paclitaxel; while similar proportions of patients on both treatments experienced an improvement in lung cancer symptoms (see below "Quality of life"). As expected, gefitinib was much better tolerated than chemotherapy (see below "Safety and tolerability").

\section{First-SIGNAL (First-line single agent Iressa versus gemcitabine and cisplatin trial in never-smokers with adenocarcinoma of the lung) trial}

Recently, results from a similar trial, comparing gefitinib with cisplatin-gemcitabine as first-line treatment in Asian never-smokers, with advanced adenocarcinoma, have been reported. ${ }^{70}$ Three hundred and nine patients, mostly women $(89 \%)$, were randomly allocated $1: 1$ to gefitinib $250 \mathrm{mg} /$ day $(\mathrm{n}=159)$ until disease progression or other criteria for discontinuation, or cisplatin-gemcitabine $(n=150)$ for a maximum of 6 cycles or until disease progression or other criteria for discontinuation. The primary endpoint was OS (Table 4). 
In the overall population, RR was $53.5 \%$ for gefitinib and $45.3 \%$ for chemotherapy (OR, 1.385, 95\% CI, 0.885-2.167, $P=0.153)$. The median OS and PFS were nearly identical, with a 1 -year PFS rate of $20.3 \%$ versus $5.0 \%$. The PFS survival curves were very similar to IPASS curves, with analogue crossing. Similarly to other studies, gefitinib improved quality of life with a better toxicity profile than chemotherapy.

The authors also conducted a subgroup study for EGFR mutations (Figure 2). Over 30\% of patients were analyzed for mutation status, giving an overall EGFR mutation rate of $43.8 \%$ (42 out of 96 patients). RR was $84.6 \%$ versus $37.5 \%$ $(P=0.002)$ for gefitinib and chemotherapy respectively in mutation positive patients, and $29.9 \%$ versus $51.9 \%$ in mutation negative $(P=0.051)$. There was no difference in OS by mutation status; however, there was some difference in PFS favoring gefitinib in mutation positive patients (8.5 versus 6.7 months; HR, 0.613, 95\% CI, 0.308-1.221, $P=0.0849$ ).

The absence of difference in OS, both in the overall and EGFR mutated populations, is most likely due to the post-study use of EGFR-TKIs in $80.7 \%$ of chemotherapy arm. Even if the study failed to reach its endpoint gefitinib allowed the achievement of a favorable response rate and disease control in Asian, non-smoker patients; especially in those who carry the EGFR mutations, so it could represent a reasonable first-line therapy for this group of patients.

These two studies highlight the importance of a selection of the patients, who are candidates for receiving gefitinib therapy. Some clinical features are related to a high rate of EGFR mutation, so it is reasonable to consider the research of these mutations in patients with these characteristics to evaluate the appropriate timing for treatment with gefitinib. Two phase III Japanese studies have been performed specifically in patients EGFR mutated to compare the efficacy of gefitinib versus chemotherapy in the first-line treatment of NSCLC (WJTOG3405 and NEJ002 trials). ${ }^{71,72}$

\section{WJTOG3405 (West Japan Thoracic Oncology Group3405) and NEJ002 (North East Japan Gefitinib Study Group002) trials}

In the WJTOG3405 trial, 172 EGFR mutated patients were randomly assigned to receive gefitinib or chemotherapy with cisplatin-docetaxel (Figure 2 ). ${ }^{71}$ The primary endpoint was PFS. The study met its endpoint, showing a median PFS of 9.2 months in the gefitinib group and 6.3 months in the chemotherapy group (HR, 0.489, 95\% CI, 0.336-0.710,
$P<0.0001)$. In the IPASS trial, PFS curves were similar in the gefitinib and the chemotherapy groups during the first 6 months of treatment, while in the present study the curves favor gefitinib at any time of treatment. RR was $62.1 \%$ and $32.2 \%$ with gefitinib and chemotherapy, respectively $(P<0.0001)$. The OS data were not available at the time of publication. A subgroup study on mutation-type-specific survival showed no statistical difference between 19 deletions and exon 21 mutations.

The WJTOG3405 trial results confirm once more gefitinib to be superior to chemotherapy in terms of RR and PFS in patients with EGFR mutations. Another prospective phase III study, comparing gefitinib to chemotherapy (carboplatin-paclitaxel) as first-line treatment in advanced NSCLC patients selected for EGFR mutation, was presented by Kobayashi and colleagues at the ASCO meeting $2009 .{ }^{72} \mathrm{At}$ present, only data on PFS and RR from an interim analysis are available. Median PFS resulted of 10.4 months in the gefitinib arm $(\mathrm{n}=98)$ and 5.5 months in the chemotherapy $\operatorname{arm}(\mathrm{n}=96)(\mathrm{HR}, 0.357,95 \% \mathrm{CI}, 0.25-0.51, P<0.001)$. Also significantly higher RR was obtained in gefitinib arm (74.5\% versus $29 \%, P<0.001)$.

\section{Gefitinib as maintenance therapy}

Due to its efficacy in advanced pretreated NSCLC patients and its mild toxicity profile, gefitinib has also been considered as maintenance therapy. Two trials tested gefitinib in unselected patients subsequently to chemotherapy (WJTOG0203) and to chemo-radiotherapy (SWOG S0023). ${ }^{73,74}$

In the West Japan Thoracic Oncology Group Trial 0203 trial, 604 patients were randomly assigned to receive a platinum-doublet chemotherapy for up to 6 cycles or the same doublet for 3 cycles followed by gefitinib as maintenance therapy until progression. ${ }^{73}$ The trial failed to meet the primary endpoint of improving OS, as there was no statistical difference between the two arms (HR, 0.86, 95\% CI, 0.72-1.03, $P=0.11)$. A small but significant improvement was seen in PFS (4.6 versus 4.3 months in gefitinib and chemotherapy arm, respectively (HR, 0.68, 95\% CI, 0.57-0.80, $P<0.001)$. In a subset analysis, a small significant difference in OS was found in the group of adenocarcinomas (HR, $0.79,95 \% \mathrm{CI}, 0.65-0.98, P=0.03)$. The explanation of these results could be related to the absence of any biological or clinical patient selection. It might be expected that there would be a greater efficacy in patients with EGFR mutation; nevertheless, it is uncertain whether there would be any benefit, administering gefitinib right after chemotherapy or at the time of disease progression. 
The South Western Oncology Group study evaluated the efficacy of a sequential therapy with gefitinib following chemo-radiotherapy in unresectable locally advanced NSCLC. ${ }^{74}$ Patients were randomized to receive gefitinib or placebo after chemotherapy with cisplatin-etoposide for 2 cycles with concomitant radiotherapy followed by 3 cycles of docetaxel consolidation. The primary endpoint was to achieve a $33 \%$ increase in median survival time rate. The study was closed after an unplanned interim analysis which showed that the planned objective was ruled out with a $P=0.0015$.

At the time of the publication, coincident with a median time of follow up of 27 months, the median OS of gefitinib arm $(\mathrm{n}=118)$ was 25 months compared to 32 months of placebo arm $(\mathrm{n}=125)(P=0.013)$. These results surprisingly showed gefitinib to be detrimental in locally advanced NSCLC patients after a standard chemo-radiotherapy. It is hard to understand the reasons of these findings. A higher rate of toxic events was reported in the experimental arm, although the moderate intensity of adverse events cannot explain the detrimental effect. Furthermore, toxicity related deaths rate was only $2 \%$ in experimental arm. The lack of selection might have contributed to the poor efficacy of gefitinib and partially explains the results, although not the reduction in OS. Another hypothesis is the potential interaction between EGFR inhibitors and radiotherapy. It is known that the concomitant use of these agents with radiotherapy enhance radiation efficacy, and it is also known that some people previously treated with radiotherapy have shown an impaired response to gefitinib. ${ }^{75,76}$ However, this hypothesis cannot completely explain the results of this study and the reasons of this detrimental effect remain unknown.

At present gefitinib has no indication as maintenance therapy in patients treated with standard therapy. It is possible that $E G F R$ mutated patients could benefit from a maintenance therapy with gefitinib, although further trials on selected patients are required.

\section{Safety and tolerability}

Gefitinib is generally well tolerated, particularly in elderly and/ or poor PS patients; it is responsible for relatively few severe side effects, as compared with conventional chemotherapeutic agents. The most common side effects are skin rash and diarrhea; less common are nausea, vomiting and anorexia. Another common toxicity is the elevation of AST/ALT, which usually regresses after discontinuation of therapy (Table 5).

Interstitial lung disease (ILD) is a rare and potentially lifethreatening side effect of gefitinib, which has been reported in some studies. The incidence of gefitinib-induced ILD is consistently higher in Japan $(1.6 \%-3.5 \%)$ as compared with other parts of the world $(0.3 \%)$, although the reason for this geographic difference is unclear. ${ }^{76,77}$ A retrospective analysis of 112 patients with NSCLC treated with gefitinib found preexisting pulmonary fibrosis to be an important risk factor for developing fatal ILD. ${ }^{76}$ Another retrospective analysis of 1,976 Japanese patients with NSCLC treated with gefitinib showed positive smoking history, male gender and the coincidence of interstitial pneumonia to be significantly associated with gefitinib-induced ILD. ${ }^{77}$

The studies reported in this article have shown evidence of tolerable toxicity profile for gefitinib (in Table 5 we report the toxicity data of the three largest studies: ISEL, INTEREST and IPASS trials). ${ }^{28,35,69}$

In the ISEL trial, the most common adverse events in the gefitinib group were of grade 1-2, whereas those of grade 3-4 were similar for gefitinib and placebo $(30 \%$ versus $27 \%$ ), with the same rate of ILD being just $1 \% .{ }^{28}$ Only $5 \%$ of patients treated with gefitinib experienced adverse events leading to withdrawal.

The INTEREST trial showed serious adverse events in $4 \%$ of patients receiving gefitinib and $18 \%$ receiving docetaxel; this led to a lower rate of drug discontinuation for gefitinib (4\% versus $11 \%$ ) and a lower rate of adverse events leading to death ( $1 \%$ versus $2 \%) .{ }^{35}$ The most common toxicities seen in the docetaxel group were hematological events: neutropenia (in $73.7 \%$ of cases with $10.1 \%$ of febrile neutropenia); asthenia (46.7\%); alopecia (35.5\%); neurotoxicity (23.9\%); and fluid retention (15.7\%). Skin rash and diarrhea were the main adverse effects seen in the gefitinib group which occurred in $49.4 \%$ and $35 \%$, respectively. Interstitial lung disease was $1 \%$ in both arms.

In the similar Japanese study (V-15-32) adverse events were consistent with those previously described; $76.2 \%$ of patients receiving gefitinib experienced rash of all grades (with $0.4 \%$ of grade $3-4$ ) and $51.6 \%$ experienced diarrhea of all grades (with $2 \%$ of grade $3-4$ ). ${ }^{36}$ ILD events were described in $5.7 \%$ of patients receiving gefitinib compared to $2.9 \%$ in the docetaxel group.

In the IPASS trial, the rate of grade 3-4 toxicities was $28.7 \%$ for gefitinib and $61 \%$ for chemotherapy. ${ }^{69}$ This led to a lower rate of dose modification (16.1\% versus $35.2 \%)$ and discontinuation of treatment $(6.9 \%$ versus $13.6 \%)$. Treatment related deaths were $3.8 \%$ in the gefitinib arm and $2.7 \%$ in the chemotherapy arm; $16(2.6 \%)$ patients treated with gefitinib developed ILD versus $8(1.4 \%)$ treated with chemotherapy. The most common adverse events were 
Table 5 Toxicity data of ISEL, INTEREST and IPASS trials ${ }^{28,35,69}$

\begin{tabular}{|c|c|c|c|c|}
\hline \multicolumn{5}{|l|}{ ISEL trial $^{28}$} \\
\hline & \multicolumn{2}{|l|}{ All grades } & \multicolumn{2}{|l|}{ Grade 3-4 } \\
\hline & Gefitinib $(1,126)$ & Placebo (562) & Gefitinib $(1,126)$ & Placebo (562) \\
\hline Skin rash & $4 \mid 3(37 \%)$ & $56(10 \%)$ & $18(2 \%)$ & I \\
\hline Diarrhea & 309 (27\%) & $52(9 \%)$ & $31(3 \%)$ & $5(1 \%)$ \\
\hline Nausea & $190(17 \%)$ & $90(16 \%)$ & $9(16 \%)$ & 2 \\
\hline Anorexia & $193(17 \%)$ & 77 (I4\%) & $26(2 \%)$ & II (2\%) \\
\hline Vomiting & 152 (I4\%) & $56(10 \%)$ & $13(1 \%)$ & 2 \\
\hline Dry skin & 128 (1 |\%) & $20(4 \%)$ & 0 & 0 \\
\hline Pruritus & $93(8 \%)$ & $27(5 \%)$ & 4 & 1 \\
\hline \multicolumn{5}{|l|}{ INTEREST trial ${ }^{35}$} \\
\hline & \multirow{2}{*}{\multicolumn{2}{|c|}{$\begin{array}{l}\text { All grades } \\
\text { Gefitinib (729) }\end{array}$}} & \multicolumn{2}{|l|}{ Grade 3-4 } \\
\hline & & & Gefitinib (729) & Docetaxel (7I5) \\
\hline Skin rash & 360 (49.4\%) & $73(10.2 \%)$ & $15(2.1 \%)$ & $4(0.6 \%)$ \\
\hline Diarrhea & 255 (35.0\%) & 177 (24.8\%) & 18 (2.5\%) & $22(3.1 \%)$ \\
\hline Asthenia & $182(25.0 \%)$ & 334 (46.7\%) & 32 (4.4\%) & 64 (9.0\%) \\
\hline Dry skin & III (I5.2\%) & $10(1.4 \%)$ & 0 & 0 \\
\hline Nausea & I 48 (20.3\%) & $187(26.2 \%)$ & $3(0.4 \%)$ & $9(1.3 \%)$ \\
\hline Neutropenia & $35(5.0 \%)$ & $514(73.7 \%)$ & I5 (2.2\%) & 406 (58.2\%) \\
\hline Febrile neutropenia & $9(1.2 \%)$ & $72(10.1 \%)$ & 9 (1.2\%) & $72(10.1 \%)$ \\
\hline Pyrexia & 69 (9.5\%) & $118(16.5 \%)$ & $2(0.3 \%)$ & $4(0.6 \%)$ \\
\hline Neurotoxicity & 49 (6.7\%) & I7I (23.9\%) & I (0.1\%) & 17 (2.4\%) \\
\hline Myalgia & $24(3.3 \%)$ & 113 (I5.8\%) & I (0.I\%) & $4(0.6 \%)$ \\
\hline Anemia & 34 (4.7\%) & $84(11.7 \%)$ & II (I.5\%) & $15(2.1 \%)$ \\
\hline Alopecia & $23(3.2 \%)$ & $254(35.5 \%)$ & 0 & 0 \\
\hline Fluid retention & $48(6.6 \%)$ & $112(15.7 \%)$ & 0 & $5(0.7 \%)$ \\
\hline \multicolumn{5}{|l|}{ IPASS trial ${ }^{69}$} \\
\hline & \multicolumn{2}{|l|}{ All grades } & \multicolumn{2}{|l|}{ Grade 3-4 } \\
\hline & Gefitinib (607) & Carboplatin-paclitaxel (589) & Gefitinib (607) & Carboplatin-paclitaxel (589) \\
\hline Skin rash & 402 (66.2\%) & 132 (22.4\%) & $19(3.1 \%)$ & $5(0.8 \%)$ \\
\hline Diarrhea & $283(46.6 \%)$ & $\mid 28(2 \mid .7 \%)$ & $23(3.8 \%)$ & $8(1.4 \%)$ \\
\hline Anorexia & | 33 (21.9\%) & $25 I(42.6 \%)$ & $9(1.5 \%)$ & $16(2.7 \%)$ \\
\hline Dry skin & 145 (23.9\%) & $17(2.9 \%)$ & 0 & 0 \\
\hline Pruritus & 118 (19.4\%) & 74 (I2.6\%) & $4(0.7 \%)$ & I $(0.2 \%)$ \\
\hline Stomatitis & $103(17.0 \%)$ & $5 \mathrm{I}(8.7 \%)$ & I (0.2\%) & $\mathrm{I}(0.2 \%)$ \\
\hline Asthenia & $102(16.8 \%)$ & $259(44.0 \%)$ & $2(0.3 \%)$ & II (1.9\%) \\
\hline Alopecia & $67(11.0 \%)$ & 344 (58.4\%) & 0 & 0 \\
\hline Myalgia & 47 (7.7\%) & $186(31.6 \%)$ & $3(0.5 \%)$ & $10(1.7 \%)$ \\
\hline Arthralgia & $39(6.4 \%)$ & $113(19.2 \%)$ & $\mathrm{I}(0.2 \%)$ & $6(1.0 \%)$ \\
\hline Nausea & $101(16.6 \%)$ & $26 \mathrm{I}(44.3 \%)$ & $2(0.3 \%)$ & $9(1.5 \%)$ \\
\hline Vomiting & 78 (I2.9\%) & $196(33.3 \%)$ & I (0.2\%) & $16(2.7 \%)$ \\
\hline Neutropenia & NA & NA & 22 (3.7\%) & $387(67.1 \%)$ \\
\hline Febrile neutropenia & I $(0.2 \%)$ & $17(2.9 \%)$ & I (0.2\%) & $17(2.9 \%)$ \\
\hline Constipation & $73(12.0 \%)$ & I 73 (29.4\%) & 0 & $\mathrm{I}(0.2 \%)$ \\
\hline Neurotoxicity & 66 (10.9\%) & 412 (69.9\%) & $2(0.3 \%)$ & $29(4.9 \%)$ \\
\hline
\end{tabular}

Abbreviation: NA, not available.

skin rash (in $66.2 \%$ of patients) and diarrhea $(46.6 \%)$ in the gefitinib group and neuro-toxic effects (69.9\%), neutropenia (67.1\%) and alopecia (58.4\%) in the carboplatin-paclitaxel group.

The favorable tolerance is particularly important for elderly patients or patients with comorbidities and poor PS. The INVITE trial showed a better safety profile for gefitinib as compared to vinorelbine in elderly patients. ${ }^{45}$ Only $9.6 \%$ had a dose interruption instead of the $21.9 \%$ in the chemotherapy group; with $21 \%$ of gefitinib patients that had a dose reduction versus $47.9 \%$ of vinorelbine arm. No toxicity related death occurred in patients treated with gefitinib. In the INSTEP trial, patients with poor performance status treated with gefitinib experienced diarrhea $(51 \%)$ and skin 
rash $(34 \%)$, but no toxicity lead to death. ${ }^{46}$ The treatment discontinuation rate was low (14\%).

\section{Quality of life}

The aim of every treatment for advanced NSCLC is purely palliative, set to achieve a prolongation in survival (whenever possible) and, above all, relief from disease symptoms without additive side effects. This rationale led investigators to consider quality of life (QoL) as an important parameter and endpoint in the trials.

The first phase II trials, such as IDEAL-1 and 2, showed that gefitinib administration improved the QoL of treated patients, as demonstrated by the Functional Assessment of Cancer Therapy-Lung (FACT-L) questionnaire used to assess it. In fact, there was a demonstration of symptom improvement rates of $40.3 \%$ and $43.1 \%$ in IDEAL-1 and 2, respectively. ${ }^{26,27}$ Symptom improvement was rapid and correlated with tumor response and survival. In IDEAL-2, at the recommended gefitinib dose of $250 \mathrm{mg} /$ day, median overall survival times were 13.6 and 4.6 months for patients with and without symptom improvement, respectively, and 9.7 months for patients with symptom improvement without tumor response. ${ }^{78}$ Among patients with stable disease or disease progression, those with symptom improvement had significantly better overall survival than those without improvement.

These data were confirmed by following trials, such as SIGN, INTEREST and V-15-32 studies. $^{34-36}$ In the SIGN trial, in which symptom improvement was a primary endpoint, QoL and symptom improvement, evaluated by FACT-L, were greater with gefitinib than docetaxel $(33.8 \%$ versus $26 \%$ and $36.8 \%$ versus $26 \%$, respectively). ${ }^{34}$ In the INTEREST trial more patients treated with gefitinib obtained a statistically significant higher rate of improvement in QoL. In fact, FACT-L total score was $25.1 \%$ versus $14.7 \%$ $(P<0.0001)$ and FACT-L TOI (Trial Outcome Index) $17.3 \%$ versus $10.3 \%(P=0.0026)$, for gefitinib and docetaxel, respectively. Similar proportion of patients improved their lung cancer symptoms (evaluated by FACT-L Lung Cancer Subscale) with gefitinib and docetaxel (20.4\% versus $16.8 \%$, respectively). ${ }^{35}$ Finally, the V-15-32 trial showed a statistically significant improvement rate in terms of QoL in patients treated with gefitinib when compared with docetaxel. ${ }^{36,79}$ FACT-L total score was $23.4 \%$ versus $13.9 \%$ $(P=0.023)$ and TOI was $20.5 \%$ versus $8.7 \%(P=0.002)$ for gefitinib and docetaxel, respectively. There were no significant differences between treatments in LCS improvement rates $(23 \%$ versus $20 \%, P=0.562)$.
In the IPASS trial, QoL was one of the secondary endpoints. ${ }^{69}$ Significantly more patients in the gefitinib group than those in the carboplatin-paclitaxel group had a clinically relevant improvement in QoL, assessed by scores on the FACT-L questionnaire (48\% versus $40 \%$; OR, $1.34,95 \% \mathrm{CI}$, $1.06-1.69, P=0.01)$ and by scores on the TOI (46.4\% versus $32.8 \%$; OR, 1.78, 95\% CI, 1.40-2.26, $P<0.001)$. Rates of reduction in symptoms, assessed on the basis of the LCS scores, were similar between patients who received gefitinib and those who received carboplatin-paclitaxel (51.5\% versus 48.5\%; OR, 1.13, 95\% CI, 0.90-1.42, P=0.30).

An agent that might improve QoL and give relief from symptoms without bringing heavy toxicity is particularly relevant for poor PS or elderly patients. For this reason QoL and pulmonary symptom relief were important parameters in INVITE and INSTEP trials. ${ }^{45,46}$ In the INVITE trial overall QoL improvement and pulmonary symptom improvement (PSI) rates were $24.3 \%$ and $36.6 \%$ (for gefitinib) and $10.9 \%$ and $31.0 \%$ (for vinorelbine), respectively. ${ }^{45}$ On the contrary, in the INSTEP trial no statistical difference was seen either for QoL improvement (21.1\% versus 20\%) and PSI (28.3\% versus $28.3 \%$ ) in patients treated with gefitinib or BSC. ${ }^{46}$

\section{Conclusions}

Gefitinib is a well tolerated anticancer agent proven to be effective in both chemotherapy-naive and pretreated NSCLC patients. Due to its efficacy and favorable toxicity profile, it can be considered as a treatment option for those patients who cannot receive standard chemotherapy because of age, comorbidities or poor performance status.

As evidenced by data obtained in the subgroup analysis of the IPASS and First-SIGNAL trials and by the results of WJTOG3405 and NEJ002 studies, specific mutations of EGFR tyrosine kinase binding domain are related to an increased response rate and progression-free survival in patients treated with gefitinib compared to standard first-line chemotherapy treatment.

The discovery of these molecular predictors opens a new way in the management of advanced NSCLC, in which gefitinib is expected to have its larger impact. In clinical practice, given the low rate of EGFR mutations in Caucasian population $(10 \%-15 \%)$, mutation analysis should be recommended in those patients who present at least one of the clinical or pathological features, which are related to a higher probability of mutation, such as female gender, non-smoking history, Asian ethnicity and adenocarcinoma histology. In patients harboring EGFR mutation, an up-front treatment with gefitinib should be considered. 
EGFR-TKI resistance represents another major issue for research. The point mutation T790M of the EGFR gene and $M E T$ amplification are known to be involved in the majority of cases of acquired resistance to gefitinib. Open questions also remain for the potential use of gefitinib as maintenance therapy. As the trials undertaken so far were performed on unselected patients there is need to assess if gene mutated patients could derive a real benefit from a subsequent therapy with TKIs administered right after chemotherapy.

\section{Disclosures}

The authors declare no conflicts of interest.

\section{References}

1. Jemal A, Siegel R, Ward E, Hao Y, Xu J, Thun MJ. Cancer Statistics, 2009. CA Cancer J Clin. 2009;59(4):225-249.

2. Travis WD, Brambilla E, Müller-Hermelink HK, Harris CC. Pathology and genetics of tumors of the lung, pleura, thymus and heart. In: Kleihues P, Sobin LH, editors. WHO Classification of Tumors. Lyon: IARC press; 2004.

3. Non Small Cell Lung Cancer Collaborative Group. Chemotherapy in non-small cell lung cancer: a meta-analysis using update data on individual patients from 52 randomised clinical trials. BMJ. 1995;311(7010):899-909.

4. NSCLC Meta-Analyses Collaborative Group. Chemotherapy in addition to supportive care improves survival in advanced non-small-cell-lung cancer: a systematic review and meta-analysis of individual patients data from 16 randomized controlled trials. J Clin Oncol. 2008;26(28):4617-4625.

5. Waters JS, O'Brien MER. The case for the introduction of new chemotherapy agents in the treatment of advanced non-small cell lung cancer in the wake of the findings of The National Institute of Clinical Excellence (NICE). Br J Cancer. 2002;87(5):481-490.

6. Scagliotti GV, De Marinis F, Rinaldi M, et al. Phase III randomized trial comparing three platinum-based doublets in advanced non-small-cell lung cancer. J Clin Oncol. 2002;20(21):4285-4291.

7. Schiller JH, Harrington D, Belani CP, et al. Comparison of four chemotherapy regimens for advanced Non-Small-Cell Lung Cancer. N Engl J Med. 2002;346(2):92-98.

8. Sandler A, Gray R, Perry MC, et al. Paclitaxel-carboplatin alone or with bevacizumab for non-small-cell lung cancer. $N$ Engl J Med. 2006;355(24):2542-2550.

9. Reck M, Von Pawel J, Zatloukal P, et al. Phase III trial of cisplatin plus gemcitabine with either placebo or bevacizumab as first-line therapy for non-squamous Non-Small-Cell Lung Cancer: AVAiL. J Clin Oncol. 2009;27(14):1227-1234.

10. Scagliotti GV, Parikh P, von Pawel J, et al. Phase III study comparing cisplatin plus gemcitabine with cisplatin plus pemetrexed in chemotherapy-naive patients with advanced-stage non-small-cell lung cancer. J Clin Oncol. 2008;26(21):3543-3551.

11. Gridelli C, Ardizzoni A, Ciardiello F, et al. Second-line treatment of advanced non-small cell lung cancer. J Thorac Oncol. 2008;3(4): 430-440.

12. Azzoli CG, Baker S Jr, Temin S, et al. American Society of Clinical Oncology clinical practice guideline update on chemotherapy for stage IV non-small-cell lung cancer. J Clin Oncol. 2009;27(36):6251-6266.

13. Bunn PA Jr, Franklin W. Epidermal Grow Factor receptor expression, signal pathways, and inhibitors in non-small cell lung cancer. Semin Oncol. 2002;29 Suppl 14:S38-S44.

14. AstraZeneca, Macclesfield, UK. Data on file 2009.

15. Albanell JR, Rojo F, Averbuch S, et al. Pharmacodynamic studies of the epidermal growth factor receptor inhibitor ZD1839 in skin from cancer patients: histopatologic and molecular consequences of receptor inhibition. J Clin Oncol. 2002;20(1):110-124.
16. Nakagawa K, Tamura T, Negoro S, et al. Phase I pharmacokinetics trial of the selective oral epidermal growth factor receptor tyrosine kinase inhibitor gefitinib ('Iressa', ZD1839) in Japanese patients with solid malignant tumors. Ann Oncol. 2003;14(6):922-930.

17. Haura EB, Sommers E, Backer A, et al. Pilot phase II study of preoperative gefitinib in early stage non small cell lung cancer with assessment of intra-tumor gefitinib levels and tumor target modulation [abstract]. J Clin Oncol. 2007;25 Suppl:S18.

18. McKillop D, McCormick AD, Millar A, et al. Cytochrome P450dependent metabolism of gefitinib. Xenobiotica. 2005;35(1):39-50.

19. Wakeling AE, Guy SP, Woodburn JR, et al. ZD1839 (Iressa): an orally active inhibitor of epidermal growth factor signaling with potential for cancer therapy. Cancer Res. 2006;62(20):5749-5754.

20. Di Gennaro E, Barbarino M, Bruzzese F, et al. Critical role of both $\mathrm{p} 27 \mathrm{KIP} 1$ and $\mathrm{p} 21 \mathrm{CIP} 1 / \mathrm{WAF} 1$ in the anti-proliferative effect of ZD1839 (Iressa), an epidermal growth factor receptor tyrosine kinase inhibitor, in head and neck squamous carcinoma cell. J Cell Physiol. 2003;195(1):139-150.

21. Cappuzzo F, Magrini E, Ceresoli GL, et al. Akt phosphorylation and gefitinib efficacy in patients with advanced non-small-cell lung cancer. J Natl Cancer Inst. 2004;96(15):1133-1141.

22. Ciardiello F, Kuroda J, Puthalakath H, et al. Inhibition of growth factor production and angiogenesis in human cancer cells by ZD1839 (Iressa), a selective epidermal growth factor receptor tyrosine kinase inhibitor. Clin Cancer Res. 2001;7(5):1459-1465.

23. Baselga J, Rischin D, Ranson M, et al. Phase I safety, pharmacokinetic, and pharmacodynamic trial of ZD1839, a selective oral epidermal growth factor receptor tyrosine kinase inhibitor, in patients with five selected solid tumor types. J Clin Oncol. 2002;20(21):4292-4302.

24. Ranson M, Hammond LA, Ferry D, et al. ZD1839, a selective oral epidermal growth factor receptor-tyrosine kinase inhibitor, is well tolerated and active in patients with solid, malignant tumors: results of a phase I trial. J Clin Oncol. 2002;20(9):2240-2250.

25. Herbst RS, Maddox AM, Rothenberg ML, et al. Selective oral epidermal growth factor receptor tyrosine kinase inhibitor ZD1839 is generally well-tolerated and has activity in non-small-cell lung cancer and other solid tumors: results of a phase I trial. J Clin Oncol. 2002;20(18):3815-3825.

26. Fukuoka M, Yano S, Giaccone G, et al. Multi-institutional randomized phase II trial of gefitinib for previously treated patients with advanced non-small-cell lung cancer. J Clin Oncol. 2003;21(12): 2237-2246.

27. Kris MG, Natale RB, Herbst RS, et al. Efficacy of gefitinib, an inhibitor of the epidermal growth factor receptor tyrosine kinase, in symptomatic patients with non-small-cell lung cancer. A randomized trial. JAMA. 2003;290(16):2149-2158.

28. Thatcher N, Chang A, Parikh P, et al. Gefitinib plus best supportive care in previously treated patients with refractory advanced nonsmall-cell lung cancer: results from a randomised, placebo-controlled, multicentre study (Iressa Survival Evaluation in Lung Cancer). Lancet. 2005;(366):1527-1537.

29. Chang A, Parikh P, Thongprasert S, et al. Gefitinib (IRESSA) in patients of Asian origin with refractory advanced non-small cell lung cancer: subset analysis from the ISEL study. J Thorac Oncol. 2006;1(8):847-855.

30. Shepherd FA, Rodrigues Pereira J, Ciuleanu T, et al. Erlotinib in previously treated non-small-cell lung cancer. $N$ Engl J Med. 2005; 353(2):123-132.

31. Hirsch FR, Varella-Garcia M, Bunn PA Jr, et al. Molecular predictors of outcome with gefitinib in a phase III placebo-controlled study in advanced non-small-cell lung cancer. J Clin Oncol. 2006;24(31):5034-5042.

32. Tsao MS, Sakurada A, Cutz JC, et al. Erlotinib in lung cancer molecular and clinical predictors of outcome. N Engl J Med. 2005;353 (2):133-144.

33. Zhu C-Q, da Cunha Santos G, Ding K, et al. Role of KRAS and EGFR as biomarkers for response to erlotinib in National Cancer Institute of Canada Clinical Trials Group study BR-21. J Clin Oncol. 2008;26(26):4268-4275. 
34. Cufer T, Vrdoljak E, Gaafar R, et al. Phase II, open-label, randomized study (SIGN) of single-agent gefitinib (IRESSA) or docetaxel as secondline therapy in patients with advanced (stage IIIB or IV) non-small-cell lung cancer. Anticancer Drugs. 2006;17(4):401-409.

35. Kim ES, Hirsch V, Mok T, et al. Gefitinib versus docetaxel in previously treated non-small-cell lung cancer (INTEREST): a randomized phase III trial. Lancet. 2008;(372):1809-1818.

36. Maruyama R, Nishiwaki Y, Tamura T, et al. Phase III study, V-15-32, of gefitinib versus docetaxel in previously treated Japanese patients with non-small-cell lung cancer. J Clin Oncol. 2008;26(26):4244-4252.

37. Lee DH, Park K, Kim JH, et al. Randomized phase III trial of gefitinib versus docetaxel in non-small cell lung cancer patients who have previously received platinum-based chemotherapy. Clin Cancer Res. 2010;16(4):1307-1314.

38. Douillard JY, Shepherd FA, Hirsh V, et al. Molecular predictors of outcome with gefitinib and docetaxel in previously treated non-small-cell lung cancer: data from the randomized phase III INTEREST Trial. $J$ Clin Oncol. Epub 2009 Dec 28.

39. Shepherd FA, Douillard J, Fukuoka M et al. Comparison of gefitinib and docetaxel in patients with pretreated advanced non-small cell lung cancer (NSCLC): Meta-analysis from four clinical trials [abstract]. J Clin Oncol. 2009;27 Suppl:S15.

40. Giaccone G, Herbst RS, Manegold C, et al. Gefitinib in combination with gemcitabine and cisplatin in advanced non-small-cell lung cancer: A phase III trial - INTACT 1. J Clin Oncol. 2004;22(5):777-784.

41. Herbst RS, Giaccone G, Schiller JH, et al. Gefitinib in combination with paclitaxel and carboplatin in advanced non-small-cell lung cancer: A phase III trial - INTACT 2. J Clin Oncol. 2004;22(5):785-794.

42. Ciardiello F, Caputo R, Bianco R, et al. Antitumor effect and potentiation of cytotoxic drugs activity in human cancer cells by ZD-1839 (Iressa), an epidermal growth factor receptor-selective tyrosine kinase inhibitor. Clin Cancer Res. 2000;6(5):2053-2063.

43. Herbst RS, Prager D, Hermann R, et al. TRIBUTE: a phase III trial of erlotinib hydrochloride (OSI-774) combined with carboplatin and paclitaxel chemotherapy in advanced non-small-cell lung cancer. J Clin Oncol. 2005;23(25):892-899.

44. Gatzemeier U, Pluzanska A, Szczesna A, et al. Phase III study of erlotinib in combination with cisplatin and gemcitabine in advanced non-small-cell lung cancer: the Tarceva Lung Cancer Investigation Trial. J Clin Oncol. 2007;25(12):1545-1552.

45. Crinò L, Cappuzzo F, Zatloukal P, et al. Gefitinib versus vinorelbine in chemotherapy-naïve elderly patients with advanced non-small-cell lung cancer (INVITE) a randomized, phase II study. J Clin Oncol. 2008;26(26):4253-4260.

46. Goss G, Ferry D, Laurie S, et al. Randomized phase II study of gefitinib compared with placebo in chemotherapy-naïve patients with advanced non-small-cell lung cancer and poor performance status. J Clin Oncol. 2009;27(13):2253-2260.

47. Argiris A, Mittal N. Gefitinib as first-line, compassionate use therapy in patients with advanced non-small cell lung cancer. Lung Cancer. 2004;43(3):317-322.

48. Lynch TJ, Bell DW, Sordella R, et al. Activating mutations in the epidermal growth factor receptor underlying responsiveness of non-smallcell lung cancer to gefitinib. N Engl J Med. 2004;350(21):2129-2139.

49. Paez JG, Janne PA, Lee JC, et al. EGFR mutations in lung cancer: Correlation with clinical response to gefitinib therapy. Science. 2004;(304):1497-1500.

50. Pao W, Miller V, Zakowski M, et al. EGF receptor gene mutations are common in lung cancers from "never smokers" and are associated with sensitivity of tumors to gefitinib and erlotinib. Proc Natl Acad Sci USA. 2004;101(36):13306-13311.

51. Han SW, Kim TY, Hwang PG, et al. Predictive and prognostic impact of epidermal growth factor receptor mutation in non - small-cell lung cancer patients treated with gefitinib. J Clin Oncol. 2005;23(11):2493-2501.

52. Mitsudomi T, Kosaka T, Endoh H, et al. Mutations of the epidermal growth factor receptor gene predict prolonged survival after gefitinib treatment in patients with non-small-cell lung cancer with post-operative recurrence. J Clin Oncol. 2005;23(11):2513-2520.
53. Takano T, Ohe Y, Sakamoto H, et al. Epidermal growth factor receptor gene mutations and increased copy numbers predict gefitinib sensitivity in patients with recurrent non-small-cell lung cancer. J Clin Oncol. 2005;23(28):6829-6837.

54. Cortes-Funes H, Gomez C, Rosell R, et al. Epidermal growth factor receptor activating mutations in Spanish gefitinib-treated non-small-cell lung cancer patients. Ann Oncol. 2005;16(7):1081-1086.

55. Taron M, Ichinose Y, Rosell R, et al. Activating mutations in the tyrosine kinase domain of the epidermal growth factor receptor are associated with improved survival in gefitinib-treated chemo-refractory lung adenocarcinomas. Clin Cancer Res. 2005;11(16):5878-5885.

56. Asahina H, Yamazaki K, Kinoshita I, et al. A phase II trial of gefitinib as first-line therapy for advanced non-small-cell lung cancer with epidermal growth factor receptor mutations. Br J Cancer. 2006;95(8):998-1004.

57. Inoue A, Suzuki T, Fukuhara T, et al. Prospective phase II study of gefitinib for chemotherapy naive patients with advanced non-small-cell lung cancer with epidermal growth factor receptor gene mutations. J Clin Oncol 2006;24(21):3340-3346.

58. Yang C, Yu C, Shih J, et al. Specific EGFR mutations predict treatment outcome of stage IIIB/IV patients with chemotherapy-naive non-smallcell lung cancer receiving first-line gefitinib monotherapy. J Clin Oncol. 2008;26(16):2745-2753

59. Sequist LV, Martins RG, Spigel D, et al. First-line gefitinib in patients with advanced non-small-cell lung cancer harboring somatic EGFR mutations. J Clin Oncol. 2008;26(15):2442-2449.

60. Inoue A, Kobayashi K, Usui K, et al. First-line Gefitinib for patients with advanced non-small-cell lung cancer harbouring epidermal growth factor receptor mutations without indication for chemotherapy. J Clin Oncol. 2009;27(9):1394-1400.

61. Sutani A, Nagai Y, Udagawa K, et al. Gefitinib for non-small-cell lung cancer patients with epidermal growth factor receptor gene mutations screened by peptide nucleic acid-locked nucleic acid PCR clamp. Br $J$ Cancer. 2006;95(11):1483-1489.

62. Yoshida K, Yatabe Y, Park JY, et al. Prospective validation of prediction of gefitinib sensitivity by epidermal growth factor receptor gene mutation in patients with non-small cell lung cancer. J Thorac Oncol. 2007;2(1):22-28.

63. Sunaga N, Tomizawa Y, Yanagitani N, et al. Phase II prospective study of the efficacy of gefitinib for the treatment of stage III/IV non-small cell lung cancer with EGFR mutations, irrespective of previous chemotherapy. Lung Cancer. 2007;56(3):383-389.

64. Tamura K, Okamoto I, Kashii T, et al. Multicentre prospective phase II trial of gefitinib for advanced non-small cell lung cancer with epidermal growth factor receptor mutations: results of the West Japan Thoracic Oncology Group trial (WJTOG0403). Br J Cancer. 2008;98(5):907-914.

65. Sugio K, Uramoto H, Onitsuka T, et al. Prospective phase II study of gefitinib in non-small cell lung cancer with epidermal growth factor receptor mutations. Lung Cancer. 2009;64(3):314-318.

66. Cappuzzo F, Ligorio C, Jänne PA, et al. Prospective study of gefitinib in epidermal growth factor receptor fluorescence in situ hybridizationpositive/phospho-Akt-positive or never smoker patients with advanced non small-cell lung cancer: The ONCOBELL trial. J Clin Oncol. 2007;25(16):2248-2255.

67. West HL, Franklin WA, McCoy J, et al. Gefitinib therapy in advanced bronchioloalveolar carcinoma: Southwest Oncology Group Study S0126. J Clin Oncol. 2006;24(12):1807-1813.

68. Lee DH, Han JY, Lee HG, et al. Gefitinib as a first-line therapy of advanced or metastatic adenocarcinoma of the lung in never-smokers. Clin Cancer Res. 2005;11(8):3032-3037.

69. Mok T, Wu YL, Thongprasert S, et al. Gefitinib or carboplatin/ paclitaxel in pulmonary adenocarcinoma. $N$ Engl J Med. 2009; 361(10):947-957.

70. Lee JS, Park K, Kim SW, et al. A randomized phase III study of gefitinib (IRESSATM) versus standard chemotherapy (gemcitabine plus cisplatin) as a first-line treatment for never-smokers with advanced or metastatic adenocarcinoma of the lung [abstract]. J Thor Oncol. 2009;4 Suppl:PRS.4. 
71. Mitsudomi T, Morita S, Yatabe Y, et al. Gefitinib versus cisplatin plus docetaxel in patients with non-small-cell lung cancer harboring mutations of the epidermal growth factor receptor (WJTOG3405): an open label, randomized phase 3 trial. Lancet Oncol. Epub 2009 Dec 21.

72. Kobayashi K, Inoue A, Maemondo M, et al. First-line gefitinib versus first-line chemotherapy by carboplatin (CBDCA) plus paclitaxel (TXL) in non-small cell lung cancer (NSCLC) patients (pts) with EGFR mutations: A phase III study (002) by North East Japan Gefitinib Study Group [abstract]. J Clin Oncol. 2009;27 Suppl:S15.

73. Takeda K, Hida T, Sato T, et al. Randomized phase III trial of platinum-doublet chemotherapy followed by gefitinib compared with continued platinum-doublet chemotherapy in Japanese patients with advanced non-small-cell lung cancer: results of a West Japan Thoracic Oncology Group Trial (WJTOG0203). J Clin Oncol. Epub 2009 Dec 28.

74. Kelly K, Chansky K, Gaspar LE, et al. Phase III trial of maintenance Gefitinib or placebo after concurrent chemoradiotherapy and docetaxel consolidation in inoperable stage III non-small-cell lung cancer: SWOG S0023. J Clin Oncol. 2008;26(15):2450-2456
75. Ochs JS. Rationale and clinical basis for combining gefitinib (IRESSA, ZD1839) with radiation therapy for solid tumors. Int J Radiat Oncol Biol Phys. 2004;58(3):941-949.

76. Takano T, Ohe Y, Kusumoto M, et al. Risk factors for interstitial lung disease and predictive factors for tumor response in patients with advanced non-small cell lung cancer treated with gefitinib. Lung Cancer. 2004;45(1):93-104.

77. Ando M, Okamoto I, Yamamoto N, et al. Predictive factors for interstitial lung Disease, antitumor response, and survival in nonsmall-cell lung cancer patients treated with gefitinib. J Clin Oncol. 2006;24(16):2549-2556.

78. Cella D, Herbst RS, Lynch TJ, et al. Clinically meaningful improvement in symptoms and quality of life for patients with non-small-cell lung cancer receiving gefitinib in a randomized controlled trial. J Clin Oncol. 2005;23(13):2946-2954.

79. Sekine I, Ichinose Y, Nishiwaki Y, et al. Quality of life and diseaserelated symptoms in previously treated Japanese patients with nonsmall-cell lung cancer: results of a randomized phase III study (V-15-32) of gefitinib versus docetaxel. Ann Oncol. 2009;20(9):1483-1488.

\section{Publish your work in this journal}

Drug Design, Development and Therapy is an international, peerreviewed open-access journal that spans the spectrum of drug design and development through to clinical applications. Clinical outcomes, patient safety, and programs for the development and effective, safe, and sustained use of medicines are a feature of the journal, which has also been accepted for indexing on PubMed Central. The manuscript management system is completely online and includes a very quick and fair peer-review system, which is all easy to use. Visit http://www.dovepress.com/testimonials.php to read real quotes from published authors.

Submit your manuscript here: http://www.dovepress.com/drug-design-development-and-therapy-journal 